\title{
Identification of potential rockfall sources using UAV-derived point cloud
}

\author{
D. S. N. A. Albarelli ${ }^{1}$ (D) O. C. Mavrouli ${ }^{1}$ (D) P. Nyktas ${ }^{1}$ (1)
}

Received: 18 November 2020 / Accepted: 24 May 2021 / Published online: 5 June 2021

(c) The Author(s) 2021

\begin{abstract}
Recent advances in remote sensing techniques and computer algorithms allow accurate, abundant, and high-resolution geometric information retrieval for rock mass characterization from 3D point clouds. The automatic application of the extracted information for local scale rockfall susceptibility assessment, where discontinuities characteristics play a major role in rocky slope stability, requires step by step logical procedures. This paper presents a novel methodology to use the extracted discontinuity set characteristics for a local scale rockfall susceptibility assessment, tailored for Uncrewed Aerial Vehicle (UAV) data acquisition. The method consists of 4 steps: (i) 3D slope model reconstruction using UAV digital photogrammetry, (ii) automatic characterization of discontinuity sets, (iii) slope stability analysis, and (iv) susceptibility assessment using a new Rockfall Susceptibility Index. The proposed method was applied to a road cut rocky slope in a mountainous area of the Samaria National Park, in Crete Island, Greece. Visual validation indicates that the areas of higher and moderate rockfall susceptibility on the 3D model of the rocky slope are adjacent to rockfall source areas marked by the presence of fallen blocks on the foot of the slope. The proposed methodological workflow presents novelties related to the use of point clouds for the estimation of the Rock Quality Designation (RQD) index, the visualization of discontinuity set spacing, the evaluation of the persistence and the Slope Mass Rating (SMR) index, as well as the incorporation of the persistence of overhangs into the rockfall susceptibility assessment and visualization.
\end{abstract}

Keywords Rockfall $\cdot$ Susceptibility $\cdot$ Rock mass $\cdot$ UAV $\cdot$ Point cloud $\cdot$ Discontinuity persistence

\section{Introduction}

In the last decades, the rocky slope mapping and stability has transitioned from two dimensional (Baillifard et al. 2003; Irigaray et al. 2003; Günther et al. 2012; Yilmaz et al. 2012) to three dimensional (Abellán et al. 2006, 2014, 2016; Gigli et al. 2014; Bonilla-Sierra et al. 2015; Assali et al. 2016; Menegoni et al. 2019; Zhang et al. 2019b; Buyer et al. 2020; Papathanassiou et al. 2020). Three-dimensional models can provide critical information for rockfall source detection and susceptibility identification along the slope height, and with a high spatial resolution (Dunham et al. 2017; Matasci et al. 2018). Given the primary importance of source identification for the rockfall hazard assessment, and of the effect of block volume for the rockfall propagation (trajectory,

D. S. N. A. Albarelli

danielseabra23@hotmail.com

1 Faculty of Geo-Information Science and Earth Observation, University of Twente, 7500 AE Enschede, The Netherlands energy, rebound height), methodologies based on the use of 3D model data need to be developed towards this end.

Moving from regional to local scale, rockfall susceptibility assessment methods variate from the GIS spatial analysis tools (Saroglou 2019) that exploit data layers including lithology and presence of geological faults, slope angle, and intensity of triggering mechanisms (earthquake and rainfall intensity maps) towards those based on the analysis of the local geological structure and strength of the rock mass (Andrea et al. 2010; Irigaray et al. 2003; Yilmaz et al. 2012). Local rockfall susceptibility assessment commonly takes place through the application of indicators such as the Slope Mass Rating index (SMR) of Romana (1993), which considers the angular relationship between the slope and discontinuities alongside basic rock mass characteristics such as discontinuity spacing, persistence, roughness, aperture, and infilling. These strategies can lead to the detection of potential source areas as points or lines to be used for the rockfall run-out simulation. Using such points or lines as potential rockfall initiation areas, although conservative, thus on the 
safe side, is not often accurate since sources areas that are eventually stable and will not generate block detachment are considered (Matasci et al. 2018). For more reliable rockfall simulation results, accurate locations of potential source areas are required, which implies better characterization of the rock mass at a local scale (Gigli et al. 2014).

The use of modern surveying techniques such as Light Detection and Ranging (LiDAR) and Uncrewed Aerial Vehicle (UAV)-based imagery and its processing with digital photogrammetry brought a new potential for rockfall sources and instability identification. These techniques allow the generation of high-resolution 3D models of the slope surface in the format of point clouds or 3D meshes, where accurate geometric information from rock masses can be extracted using manual procedures or automatic routines via computer algorithms, among them open-source software (Guo et al. 2019; Riquelme et al. 2014a, 2015, 2018; Slob 2010; Sturzenegger et al. 2011; Ünlüsoy and Süzen 2020; Zhang 2019a).

Although many publications deal with the feature extraction of the rock mass characteristics from point clouds, few works, such as Matasci et al. (2018) and Dunham et al. (2017), have developed a methodology on how to apply these features for automatic rockfall source identification. Papathanassiou et al. (2020) provided a comprehensive methodology to characterize a 3D model (point cloud) of a rock mass by means of the Rock Mass Rating and Slope Mass Rating indices; nevertheless, the identification of potential rockfall source areas were made only by visual assessment without incorporating the extracted features of the 3D model in an integrated workflow.

Moreover, attempts to identify the extent of potentially detachable rock masses directly on a 3D point cloud environment are scarce (Bonneau et al. 2019; Chen et al. 2017; Farmakis et al. 2020; Menegoni et al. 2020). For instance, recent studies on kinematic stability analysis consider the angular relationship between the rock mass discontinuities and the slope in stereogram plotting (Alameda-Hernández et al. 2019; Menegoni et al. 2019; Wang et al. 2019), but the extent of the areas to be affected on the point cloud cannot be directly deducted from that. Such information is important for an effective rockfall hazard analysis, where usually the source areas are not refined across the slope, and could therefore compromise the propagation results.

Recent contributions for the rockfall susceptibility assessment on LiDAR-derived point clouds have been made by Dunham et al. (2017) and Matasci et al. (2018). Dunham et al. (2017) developed the Rockfall Activity Index (RAI), a slope morphology-based index, allowing the centimeter accurate point cloud to be classified into increasing rockfall activity levels based on a simple logic tree algorithm. Matasci et al. (2018) developed a routine to quantify the rockfall susceptibility at a local to a sub-regional scale, covering up to thousands of square meters. The final output is a classified point cloud, providing the locations of susceptible areas, considering planar, wedge, and toppling failure mechanisms and overhanging parts of the rock cliff. The routine to quantify rockfall susceptibility was later applied in an augmented reality environment by Zhang et al. (2019b). Even though the works of Dunham et al. (2017) and Matasci et al. (2018) consider the presence of overhangs for the susceptibility analysis, the extension of the overhangs was not taken into account. The extension of the overhangs is an indication of how large the unstable areas are and therefore constitute relevant information for rockfall hazard.

The objective of this work is to present a methodology that uses UAV imagery-derived point clouds to identify and visualize potential rockfall sources on rocky walls. The proposed methodology consists of four steps: (i) 3D point cloud generation, (ii) discontinuity set characterization on the point cloud, (iii) slope stability analysis by means of the SMR index, and (iv) calculation of the Rockfall Susceptibility Index on the 3D model of the rocky slope, as indicative of rockfall stability. The Rockfall Susceptibility Index incorporates as parameters the overhangs, the SMR index of Romana (1993), the discontinuity set persistence, and spacing.

Different from the previous works, the proposed methodology consists of using an index for rockfall susceptibility assessment, which is based on data that can be extracted from already available discontinuity characterization algorithms for point clouds. However as these algorithms rarely incorporate this information into a unified methodology to visually indicate potential rockfall sources on the slope model, this work focuses on that. A procedure to visualize the spacing, persistence, and the SMR index values directly on the point cloud is shown, instead of the commonly used non-visual (numerical) data. As a part of the presented methodology, we also propose the assessment of the Rock Quality Designation (RQD), according to Deere and Deere et al. (1989), exclusively by data obtained by the point cloud model of the slope surface. Finally, for the visualization of the rockfall sources, we suggest the incorporation of the extension of overhangs, considering that larger overhang areas are indicative of higher hazard.

As the aim here was to develop a methodology which is mostly based on data extracted from the 3D model of the slope, the innovative use of techniques for the calculation or visualization of the involved parameters is also described and explained in detail in the following sections.

The proposed methodology was applied to a road cut rocky slope in the wider mountainous area of the Samaria National Park, in Crete Island, Greece. The validation of the susceptibility results is based on the visual observation of past events, which indicates that the areas calculated as being of higher and moderate rockfall susceptibility on the 
slope are adjacent to past rockfall sources, that have led to relatively more and larger deposited blocks on the foot of the slope. The approach herein proposed is suitable for rocky slopes along transportation corridors such as road cuts and railways, open-pit mines, and rock cliffs at a local scale (up to hundreds of square meters).

\section{Case study}

To develop and test the proposed methodology, we worked on a road cut situated in the broader context of Samaria National Park, in Crete, Greece. The latter is a park located in western Crete, on the southern slope of the White Mountains (Fig. 1), a World's Biosphere Reserve as established by UNESCO in 1981. Tectonic activity, erosion, and karstification shaped the mountainous landscape of the area (Vogiatzakis and Rackham 2008), creating plenty of narrow, tall, and vertical rocky slopes, with Samaria Gorge being the steepest, tallest, and narrowest opening (Spanos et al. 2008).

The island of Crete is part of the Hellenic arc, a lithospheric structure originated by an orogenic process due to the convergence of the African and Eurasian tectonic plates (Manutsoglu et al. 2003). This lithospheric framework favors seismicity in the island, with earthquake intensity ranging from 0.12 to 0.24 of acceleration coefficient $g$ (Saroglou 2019). In the past century, the closest epicenters to Crete had a magnitude of up to 6.3 according to the earthquake catalogue of Makropoulos et al. (2012).
Prevalent in the geological setting are the high pressurelow temperature metamorphic rocks belonging to the Plattenkalk unit overlain by the Phyllite-Quartzite unit (Seidel 2003). At a regional scale, the Plattenkalk unit incorporates the Mavri formation (Lower Liassic) in the lower part of the stratigraphic column up to the Aloides formation (Eocene) in the upper part (Manutsoglu et al. 2003), which consists mainly of cherty calcite marbles, dolomite, phyllite, and a calcareous metaflysh (Seidel 2003).

The rainfall season is mainly concentrated between September and April, with a mean annual precipitation of $1244 \mathrm{~mm}$ estimated from 7-year data recorded by the meteorological station in the Samaria Gorge (National Observatory Athens 2020).

\section{Field data collection}

The studied rocky slope is located on a road cut approximately $1620 \mathrm{~m}$ above mean sea level, between the entrance of the Gorge and the Kallergis mountain refugee (Fig. 1), a place to host hikers and climbers. The rocky slope is approximately $14 \mathrm{~m}$ in height, $46 \mathrm{~m}$ in lateral extension, and has an average slope angle of $51^{\circ}$ towards the road. It consists of dark grey platy limestone with bedding planes of decametric thickness, and with occasional centimetric intercalations of quartz or calcite.

Four principal discontinuity sets were identified (Fig. 2) and their orientation was obtained manually using a geological compass, except DS 4 (Table 4) since it was not visually identified during the field investigations as being
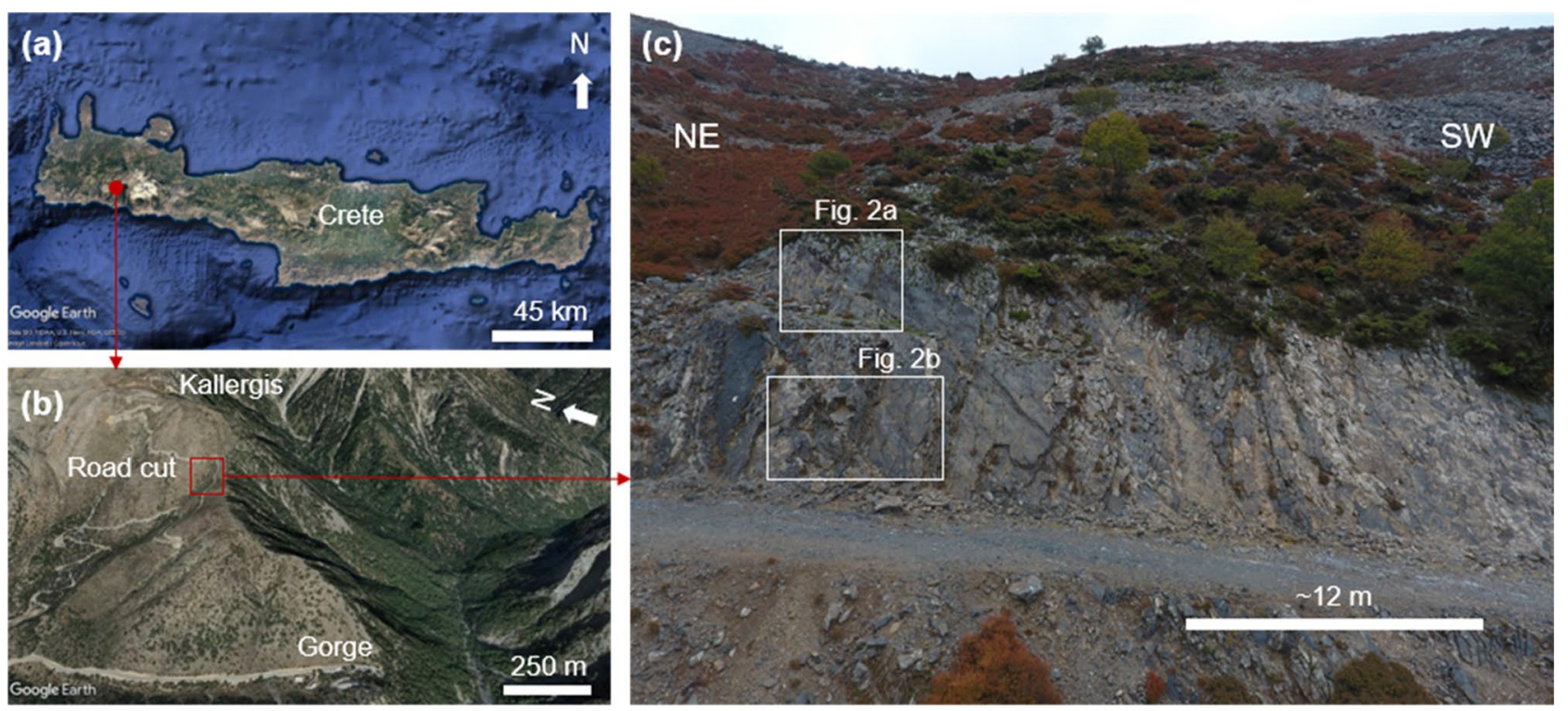

Fig. 1 (a) Location of the study area (red) in western Crete, Lefka Ori mountain at $35^{\circ} 19^{\prime} 14.92^{\prime \prime} \mathrm{N} / 23^{\circ} 55^{\prime} 40.81^{\prime \prime} \mathrm{E}$ (latitude/longitude). (b) Road cut chosen as a case study between the entrance to Samaria
Gorge in the bottom and Kallergis refugee at the top of the mountain. (c) UAV image of the rocky slope on the road cut. Source: (a and b) Google Earth, September 1, 2018 

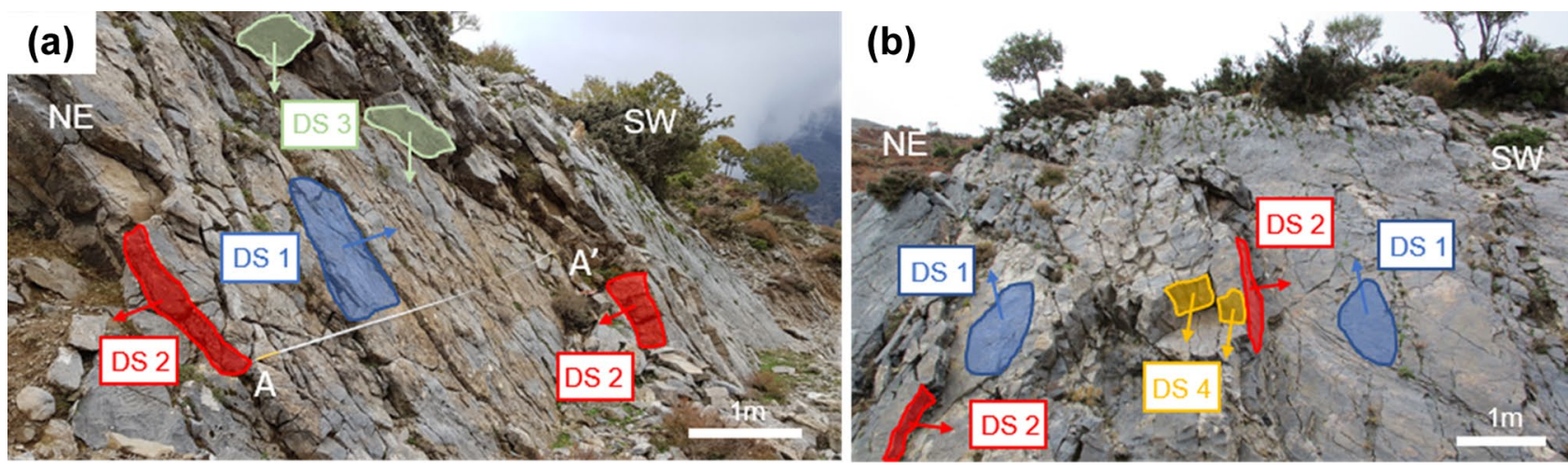

Fig. 2 Identified discontinuity set with normal vector in the upper (a) and bottom (b) of the rocky slope. The scanline in a has a total of 4-m extension from $\mathrm{A}$ to $\mathrm{A}^{\prime}$

significantly different from other discontinuity sets. The compass measurements were obtained along $2 \mathrm{~m}$ of a total $4 \mathrm{~m}$ long scanline in the upper part of the rocky slope as well as on specifically chosen surfaces since the scanline did not intersect all the discontinuity sets.

The discontinuity sets are almost perpendicular to each other, forming parallelepiped shaped rock blocks. The most representative discontinuity set is the bedding plane (DS 1) with the same dip as the slope surface $\left(51^{\circ}\right)$. Small rockfalls constitute the main process of mass wasting, where the rock blocks bounded by DS 2 laterally and by DS 3 and DS 4 in the front and back, slide on the bedding plane surface (DS 1) in a planar failure mechanism followed by a free fall. The block fragments measured at the bottom of the slope have a volume ranging from $0.064 \mathrm{~m}^{3}$ to $0.001 \mathrm{~m}^{3}$, or edge dimensions from 40 to $5 \mathrm{~cm}$. Vegetation is abundant above the slope and some small bushes are present on the slope surface too. Chemical weathering is not prominent and no seepage was observed during the fieldwork.

The risk of rockfalls in this area is related to vehicle transiting the road connecting the village of Omalos, next to the entrance of Samaria Gorge and the Kallergis Refugee. Although this road is not highly transited, this slope was selected as an example for the application of the method and the processing of the point cloud, to be further extended to cut and natural slopes where risk is higher, and thus susceptibility and hazard analysis are essential.

\section{Methodology}

The proposed methodological workflow consists of four steps (Fig. 3): (i) 3D slope model reconstruction using UAV digital photogrammetry, (ii) automatic characterization of discontinuity sets, (iii) slope stability analysis, and (iv) rockfall susceptibility assessment.

\section{The 3D slope model reconstruction using UAV digital photogrammetry}

The red/green/blue (RGB) images taken with a UAV platform are used as input for the reconstruction of the 3D slope model as a point cloud employing Structure from Motion (SfM), a photogrammetry technique that uses computer algorithms to extract key points in overlapping images taken from multiple view angles to create 3D models (Westoby et al. 2012). Once the point cloud is generated, points that do not represent the surface of the slope, such as those corresponding to vegetation, soil, and rock fragments in the surroundings, should be removed to reduce the size of the file and to avoid misclassification of the automatic detection of the discontinuity surface, therefore improving the results of the classification (Menegoni et al. 2019; Riquelme et al. 2018).

\section{Automatic characterization of discontinuity sets}

The discontinuity set characterization performed onto the 3D point cloud is performed using the open-source software Discontinuity Set Extractor (DSE) developed in MATLAB by Riquelme et al. (2014a), and consists of the semiautomatic identification and definition of the discontinuity sets (DS). In particular, for each DS it is possible to obtain the dip, the dip direction, the persistence, and the normal spacing.

The discontinuity set dip and dip direction are obtained semi-automatically in the DSE software in three main steps following the methodology proposed by Riquelme et al. (2014a): local curvature calculation, statistical analysis of the planes, and cluster analysis. In this approach, each cluster is described mathematically as a plane equation and visually as a group of 3D points with the same local normal vector orientation. In practical terms, each cluster represents an exposed surface on the rocky slope corresponding to a 


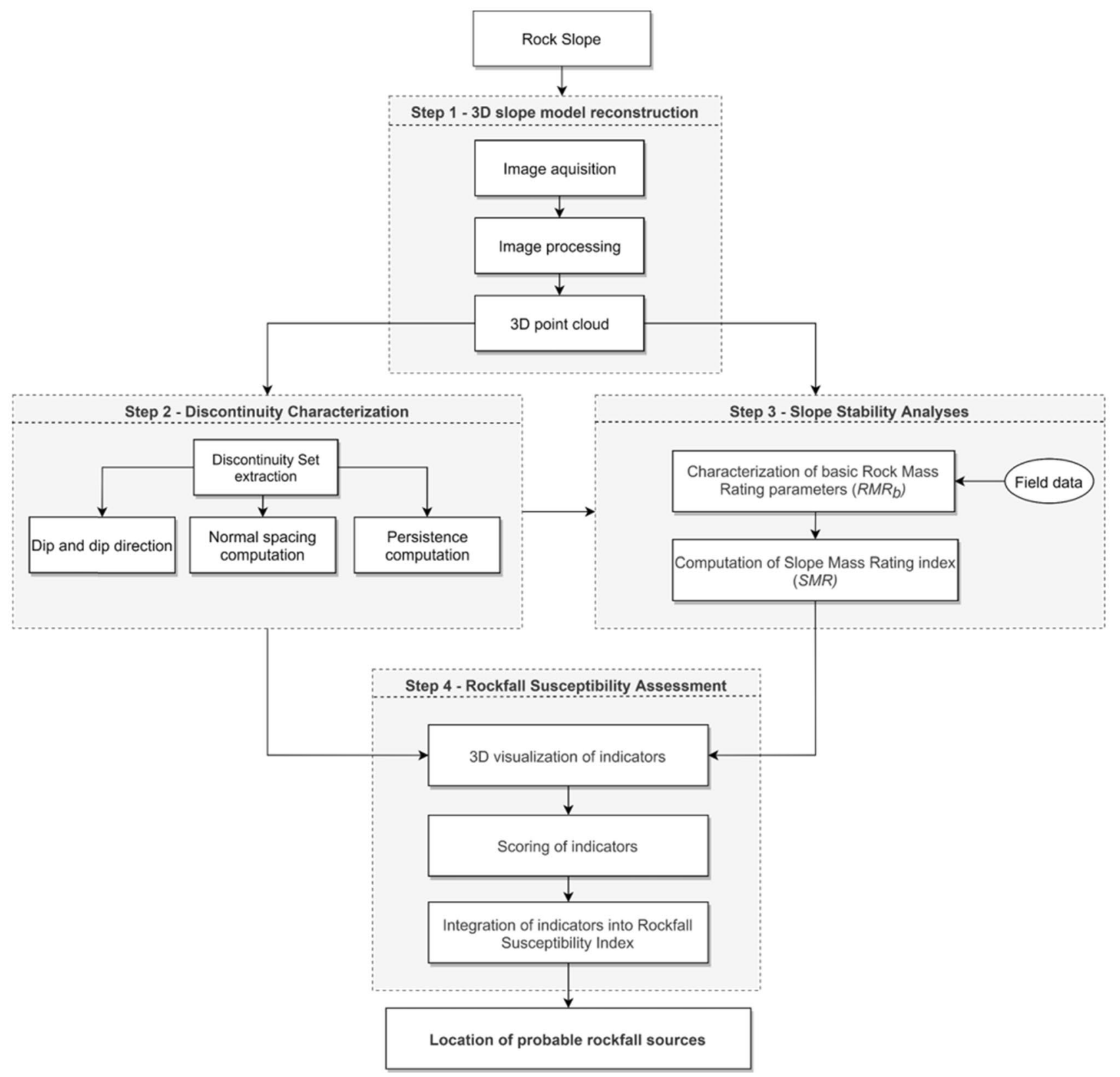

Fig. 3 Proposed methodological workflow

discontinuity and it is colorized with the same color as the other clusters assigned to the same discontinuity set. The output is a.txt file of the classified 3D point cloud, containing for each point, the following attributes: 3D coordinates $(X, Y, Z)$, Discontinuity Set id (Ds id), Cluster id (Cl id), and Cluster plane equation parameters $(A, B, C, D)$. The main limitation of this approach is that only the $3 \mathrm{D}$ points belonging to exposed surfaces of the rocky slope are identified as discontinuity surfaces.

An algorithm developed by Riquelme et al. (2015) and implemented in the DSE software allows the automatic normal spacing computation from the results of the discontinuity set dip and dip direction (the classified 3D point cloud). The parameter $D$ for each cluster represents its position in space, and thus, the normal spacing is computed as the orthogonal distance between the position of neighboring clusters. The user can choose to compute the normal spacing considering two scenarios: full persistent or non-persistent discontinuities (see Riquelme et al. 2015 for full description). The output is a.txt file containing: the Discontinuity Set id ( $D s i d$ ), the Pairs of neighboring clusters id $(\mathrm{Cl}$ id $)$, and the Spacing between clusters as the orthogonal distance (m). This computational approach requires that the normal vector of each cluster plane is equal to the normal vector of the discontinuity 
set (Riquelme et al. 2015). In practical terms, it implies that the studied slope in which this method is applied should have parallel discontinuities on a given set.

The computation of the discontinuity persistence is automatically performed also from the classified $3 \mathrm{D}$ point cloud using the DSE software, according to the methodology developed by Riquelme et al. (2018). If the discontinuities in the studied slope are fully persistent, the user can set a $k$ threshold to merge coplanar clusters and form a new merged cluster for the computation of persistence. If the discontinuities are non-persistent, $\mathrm{k}$ can be set as 0 so that each cluster is considered as an individual discontinuity for the computation. For each cluster (if $\mathrm{k}=0$ ) or merged cluster (if $\mathrm{k}>0$ ), the persistence is computed in three directions (dip, dip direction, and length of the maximum chord) and in terms of the area of the cluster. These persistence values are not visualized in the 3D point cloud but are provided numerically in a.txt file as an output from DSE software, similarly to the spacing calculation, which includes the following data: Discontinuity Set id ( $D s$ id), Clusters id $(\mathrm{Cl}$ $i d)$, persistence along the dip $(\mathrm{m})$, persistence along the dip direction $(\mathrm{m})$, persistence along the maximum length $(\mathrm{m})$, and the persistence in terms of area $\left(\mathrm{m}^{2}\right)$. As the output files from the discontinuity set normal spacing and persistence computation do not have the 3D position of the cluster, the visualization of these rock mass characteristics is not plotted in the point cloud environment. On step (iv) of the methodology, we propose a workflow chart (Fig. 4) for their visualization directly on the $3 \mathrm{D}$ model as well as on the use of these characteristics as indicators for the rockfall susceptibility assessment.

\section{Slope stability analysis}

The rocky slope stability is analyzed by means of the SMR index for each discontinuity set, using the open-access calculator SMRTool developed by Riquelme et al. (2014b). This procedure requires first the characterization of basic geomechanical parameters of the rock mass for the Rock Mass Rating- $R M R_{b}$ of Bieniawski (1989). For this case study, no drill cores were available for the calculation of the RQD index, one of the geomechanical parameters for the $R M R_{b}$. An alternative to calculate the RQD index directly on the 3D point cloud is proposed here, which follows a similar procedure as described by Deere and Deere (1989) for drill cores. Our approach consists of selecting sections on the surface of the slope which are perpendicular to the prevalent discontinuity sets, so that the rock blocks formed by the intersection of trace lengths in the slope surface larger than $100 \mathrm{~mm}$ are summed and afterward divided by the total length of the section. The obtained RQD index was afterward validated by the estimated RQD index from the correlation to the volumetric discontinuity count $J_{V}$ for cubic shape rock fragments (Eq. 1), after Palmstrom (2005):

$R Q D=110-2.5 J_{V}$

where the $J_{V}$ is calculated as the inverse sum of ( $n$ ) discontinuity sets having each a mean discontinuity set spacing $S_{n}$ as shown in Eq. 2:

$J_{V}=\frac{1}{S_{1}}+\frac{1}{S_{2}}+\cdots+\frac{1}{S_{n}}$

\section{Rockfall susceptibility assessment}

A novel approach for the integration of geomechanical properties of the rock mass on the 3D model to provide a visualization of the rockfall susceptibility assessment in 3D is described in Fig. 4. First, the geomechanical properties are evaluated as susceptibility indicators and visualized. Then the Rockfall Susceptibility Index is calculated, integrating these indicators. Using the proposed procedure, potential rockfall sources and their susceptibility can be visualized directly on the point cloud.

The following susceptibility indicators are used:

- The presence of overhangs $\left(I_{o}\right)$, indicating a lack of support for the overlying rock mass. First, the classified 3D point cloud is overlaid with the RGB point cloud to evaluate which cluster $(\mathrm{Cl}$ id) represents overhanging surfaces belonging to the corresponding discontinuity set. For those clusters, the value of 1 is given to all its 3D points as a new attribute on the classified 3D point cloud whereas the value of 0 is given to all the other clusters.

- The minimum spacing between discontinuities $\left(I_{S}\right)$, as an indicator of the rock mass quality. Discontinuities with smaller spacing translate to a poorer quality rock and thus a higher probability for rock detachment. In computing the discontinuity spacing, a given cluster can have more than one normal spacing value if it has more than one neighboring cluster (Fig. 5). To account for a conservative scenario, the value of the smallest spacing is given to all the 3D points belonging to that given cluster as a new attribute on the classified 3D point cloud.

- The discontinuity persistence in terms of maximum length $\left(I_{P}\right)$, indicating the extent of lack of support for the overlying rock mass. Focus on the persistence of the DS 1, DS 2, DS 3, and DS 4 is also given here, as it indicates areas of weak lateral support of the rock mass and areas being more susceptible to rockfalls. To account for a conservative scenario, the length of the maximum chord computed with the DSE software was used. The degree in which this assumption is conservative or realistic has to be verified by observation of the study site in situ or 


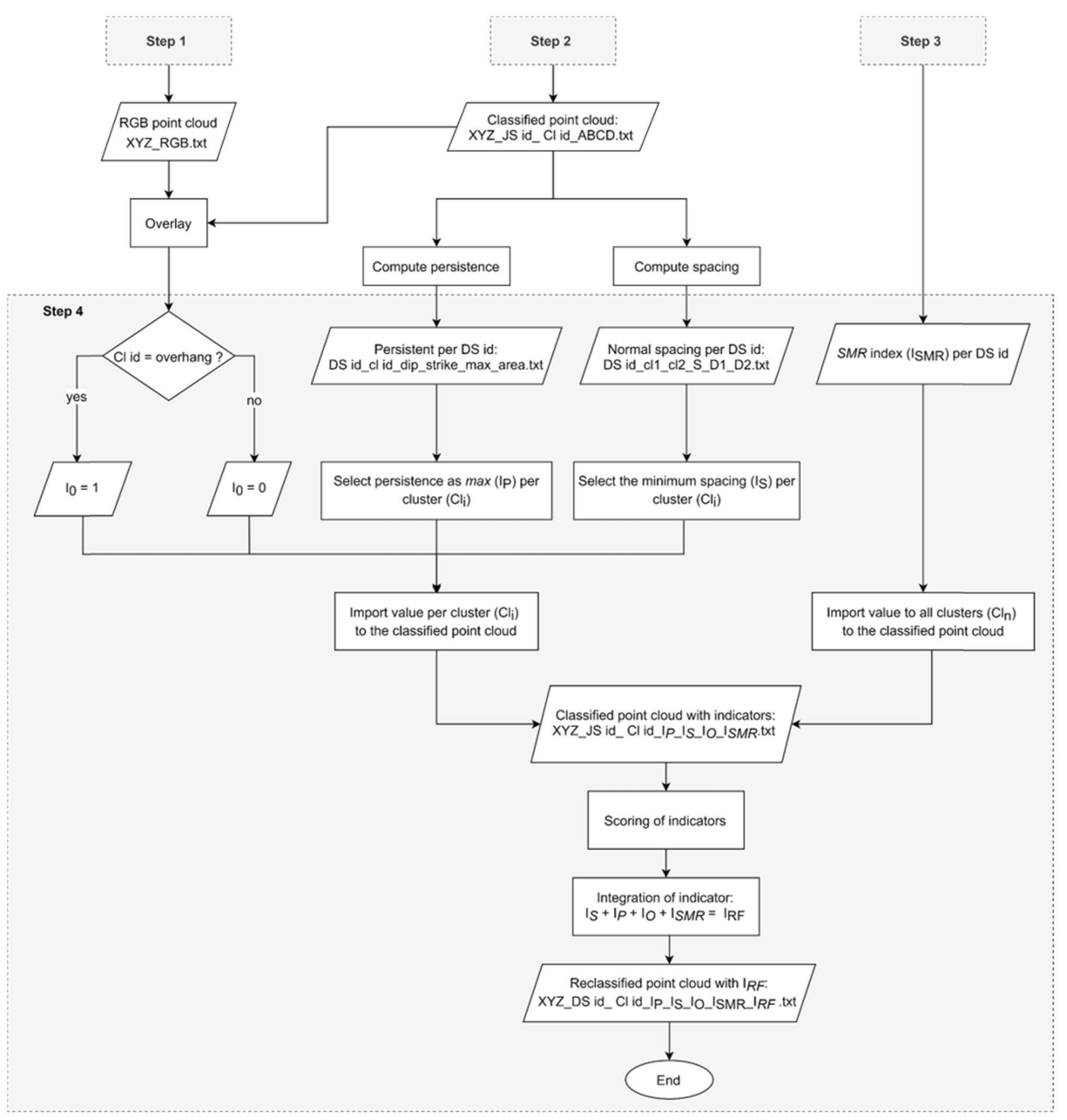

Fig. 4 Flowchart for rockfall susceptibility assessment

virtually on the point cloud. The value of persistence of each cluster was given to all the 3D points belonging to that cluster of a particular discontinuity set, as a new attribute in the.txt file of the classified 3D point cloud.

- The SMR index $\left(I_{S M R}\right)$, indicating instabilities mainly based on kinematic criteria, without directly considering the shear resistance of the rock mass. In this approach, the computed SMR class of each discontinuity set is assigned to all its clusters and corresponding 3D points, also as a new attribute in the classified 3D point cloud.

Considering the aforementioned indicators, each point comes with the following attributes, with their respective range of values, as explained:

- 3D coordinates $(\mathrm{X}, \mathrm{Y}, \mathrm{Z})$ 


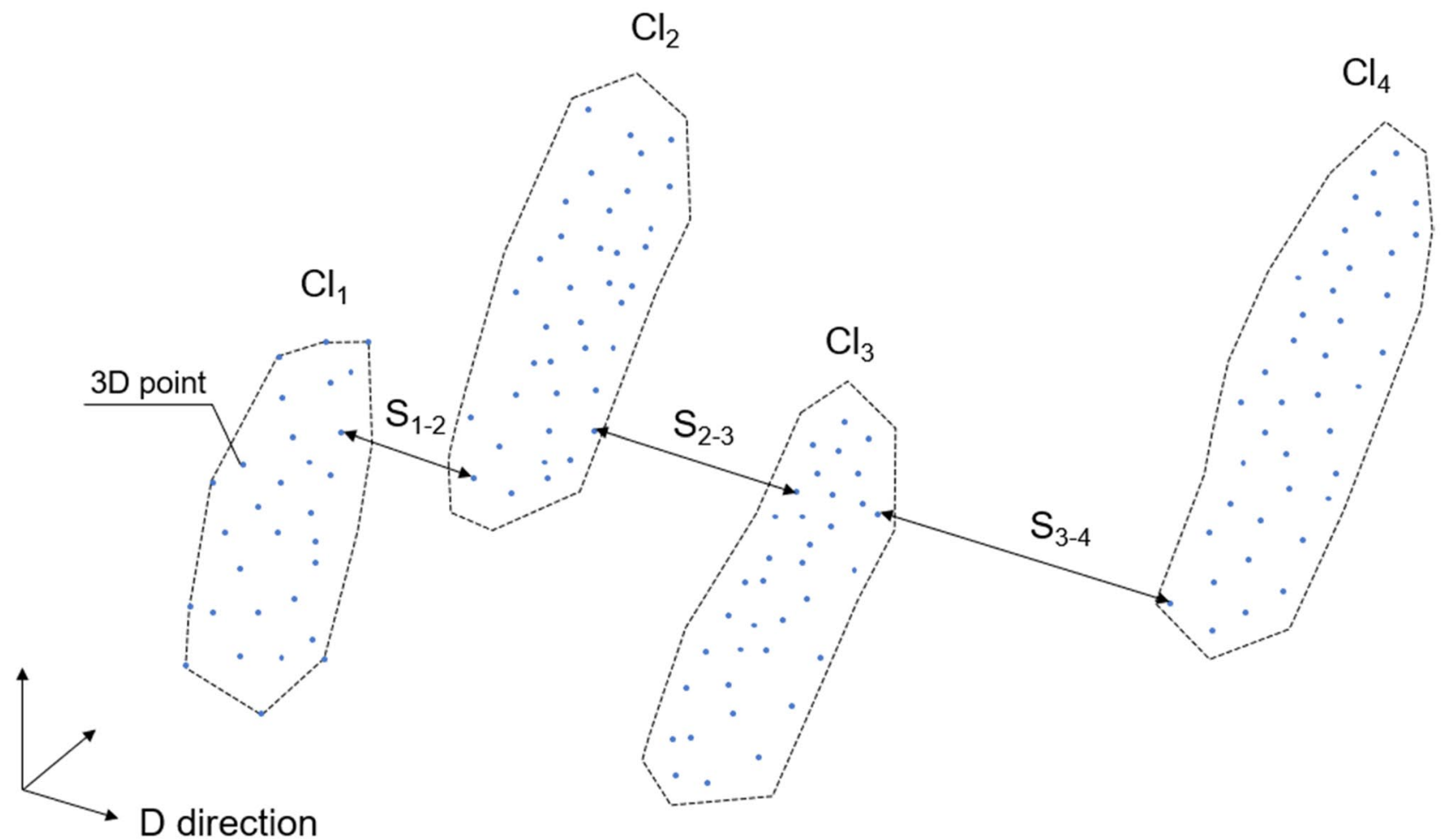

Fig. 5 Schematic representation of normal spacing calculation (S) for non-persistent discontinuity of a given discontinuity set. In this example, 4 clusters $(\mathrm{Cl})$ are separated by different positions in space D. $\mathrm{Cl}_{2}$ has a smaller normal spacing $\mathrm{S}_{1-2}$ computed to $\mathrm{Cl}_{1}$ compared to the spacing $\mathrm{S}_{2-3}$ to cluster $\mathrm{Cl}_{3}$. A similar scenario applies for $\mathrm{Cl}_{3}$, where

- Discontinuity Set id, $D$ s id: $1,2 \ldots \mathrm{n}$

- Cluster id, $\mathrm{Cl}$ id: $1,2 \ldots \mathrm{n}$

- Overhang indicator $\left(I_{o}\right)$ : present $\left(I_{o}=1\right)$ or absent $\left(I_{o}=0\right)$

- Spacing indicator $\left(I_{S}\right)$ : numerical value in $\mathrm{m}$

- Persistence indicator $\left(I_{P}\right)$ : numerical value in $\mathrm{m}$

- SMR index $\left(I_{S M R}\right)$ : class values ranging from completely stable (I) to completely unstable (V)

The point attributes can be visualized at the $3 \mathrm{D}$ space by setting them as scalar fields using a point cloud visualization software. Here, CloudCompare (2020) v.2.10.2. is used. For each attribute $\left(I_{o} I_{S} I_{P} I_{S M R}\right)$ of a point, a score of 0,1 , or 2 is given. The scores are defined based on the influence of the attribute on the quality of the rock mass $\left(I_{S}\right)$, the stability of the slope $\left(\mathrm{I}_{S M R}\right)$, and the lack of support for overlaying rock masses $\left(I_{o}, I_{P}\right)$. For instance, lower values of normal spacing indicate lower rock mass quality according to the RMR index (Bieniawski 1989), and therefore receive a higher value in the scoring for susceptibility. Discontinuities with SMR classes considered unstable according to Romana (1993) were also given a high value of scoring. The presence of overhangs scores higher too. the computed spacing $\mathrm{S}_{2-3}$ to $\mathrm{Cl}_{2}$ is smaller than the spacing $\mathrm{S}_{3-4}$ to cluster $\mathrm{Cl}_{4}$. In our approach, all the $3 \mathrm{D}$ points of $\mathrm{Cl}_{2}$ receive the value of $\mathrm{S}_{1-2}$ as a new attribute whereas all the 3D points of $\mathrm{Cl}_{3}$ receive the value of $S_{2-3}$

The scores are empirically established as shown in Table 1 . For the $I_{S}$ and $I_{P}$, the assessment was carried out by visualizing the numerical value on the $3 \mathrm{D}$ space and checking the range of values of $I_{S}$ and $I_{P}$ in areas of low (scoring 0 ), moderate (1), or high susceptibility (2). For the $\mathrm{I}_{S M R}$, the classes which are proposed by Romana (1993) were used: class I described as no failures was considered as of low susceptibility (scoring 0), class II and III described with some failure of blocks as of moderate (1), and the remaining classes IV and $\mathrm{V}$ with bigger failures as of high susceptibility (2). For the $I_{o}$, overhang surfaces $\left(I_{o}=1\right)$ were characterized as highly susceptible (scoring 2 ), whereas the rock

Table 1 Indicator scores for the rockfall susceptibility assessment

\begin{tabular}{llll}
\hline Indicators & \multicolumn{3}{l}{ Scores } \\
\cline { 2 - 4 } & High (2) & Moderate (1) & Low (0) \\
\hline$I_{S}$ & $<0.50 \mathrm{~m}$ & $0.50-1 \mathrm{~m}$ & $>1 \mathrm{~m}$ \\
$I_{P}$ & $>1 \mathrm{~m}$ & $1-0.50 \mathrm{~m}$ & $<0.50 \mathrm{~m}$ \\
$I_{S M R}$ & Classes VI and V & Classes II and III & Class I \\
$I_{O}$ & Present & n.a & Absent \\
\hline
\end{tabular}

n.a. not applicable 


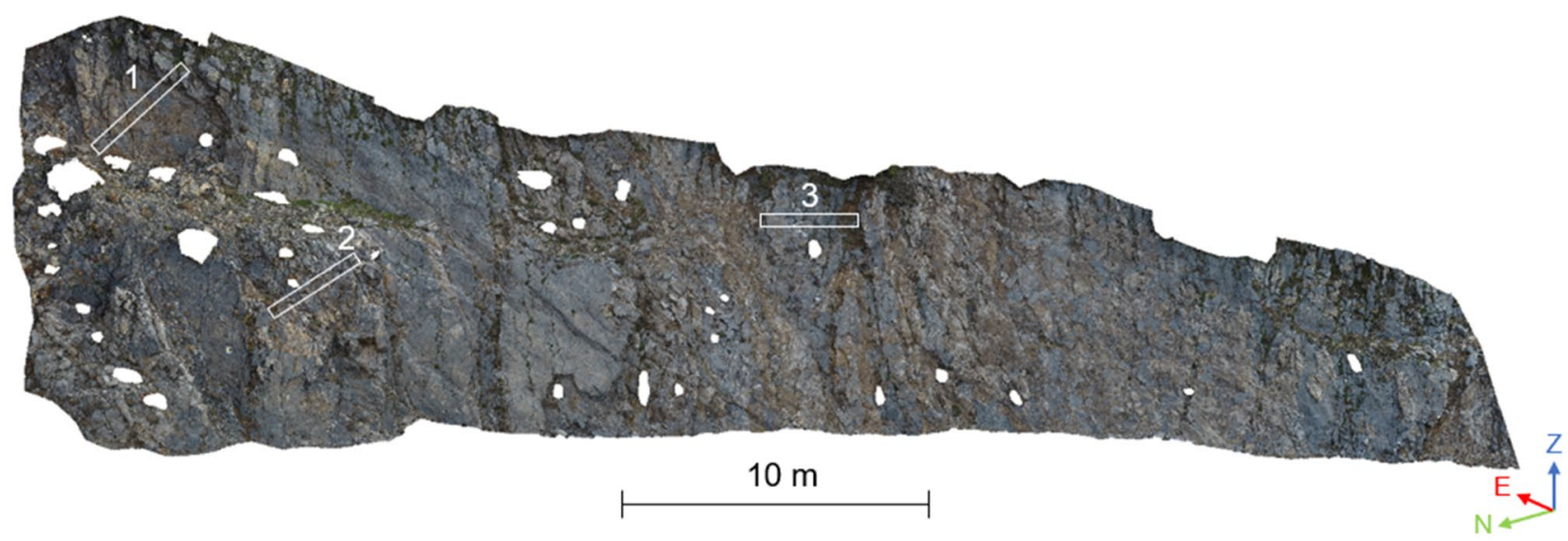

Fig. 6 RGB 3D point cloud of the studied rocky slope. The 3 white sections are the chosen location for the RQD index calculation described in Fig. 11

surfaces corresponding to all the other discontinuities that are not overhangs $\left(I_{o}=0\right)$ were characterized as low susceptibility (0). The use of these thresholds was further verified and validated, after application to the case study.

The scored indicators are summed up with the same weight to give the Rockfall Susceptibility Index $I_{R F}$ (Eq. 3) ranging from 0 to 8 :

$I_{R F}=I_{S}+I_{P}+I_{S M R}+I_{O}$

The classification of $I_{R S}$ into low, moderate, and high susceptibility levels depends on the specific site characteristics of a given slope and thus requires each time adjustment to the local conditions. In this case study, the $I_{R S}$ was classified into three susceptibility classes: low for scores up to 3 , moderate from 3 to 5 , and high from 5 to 8 , assuming an equivalent distribution of the scores into the classes. A higher index in a particular area in the slope does not guarantee that a rock detachment will occur in the future, but it is rather an indication of areas in the slope more prone than others based on the considered indicators (overhangs, spacing, persistence, and SMR class). The highlighted as highly

Table 2 Input parameters used for discontinuity set extraction in the DSE software

\begin{tabular}{ll}
\hline Parameter & Value \\
\hline K nearest neighbor $-\mathrm{k}_{\mathrm{nn}}$ & 20 points \\
Tolerance for the coplanarity test $-\eta_{\max }$ & 0.3 \\
Number of bins for the density analysis—nbin & 64 \\
User-defined number of discontinuity sets—DS & 4 \\
Minimum angle between principal poles $-\gamma_{1}$ & $20^{\circ}$ \\
Maximum angle between a pole and its principal pole & $30^{\circ}$ \\
$\quad$ cone filter) $-\gamma_{2}$ & \\
Minimum number of points per cluster-ppc & 100 points \\
Cluster distribution threshold for cluster alignment- $-\mathrm{k}$ & 0
\end{tabular}

and moderate susceptible areas on the $3 \mathrm{D}$ point cloud can be afterward used for the next steps of rockfall hazard assessment including detailed block volume calculation, intensity, and trajectory of fallen blocks.

\section{Application to a rocky slope in Samaria National Park, Crete}

\section{The 3D slope model reconstruction using UAV digital photogrammetry}

The UAV data acquisition of RBG images was carried out using the inbuilt 12.4-megapixel resolution camera on board of a DJI Phantom 4 quadcopter. A manual flight mode was performed in which the UAV stops in the air to capture the image and then moves to the next spot to acquire the next image, instead of taking images while moving. This procedure reduces the chance of having motion-blurred images. Variable oblique views of the rocky slope were preferred since it provides a better point cloud resolution, for the given geological structure, and avoids occlusion. This was particularly important in this case study to capture the overhanging areas of the slope, as they are required for the rockfall susceptibility assessment. The distance from the UAV to the

Table 3 Extracted discontinuity sets by the DSE software

\begin{tabular}{llll}
\hline Discontinuity set & $\begin{array}{l}\text { Dip direction/ } \\
\operatorname{dip}\left({ }^{\circ}\right)\end{array}$ & Clusters & Points assigned \\
\hline DS 1 & $311 / 51$ & 190 & $3,459,156$ \\
DS 2 & $38 / 78$ & 269 & 106,408 \\
DS 3 & $178 / 62$ & 143 & 39,530 \\
DS 4 & $126 / 63$ & 162 & 40,361 \\
\hline
\end{tabular}




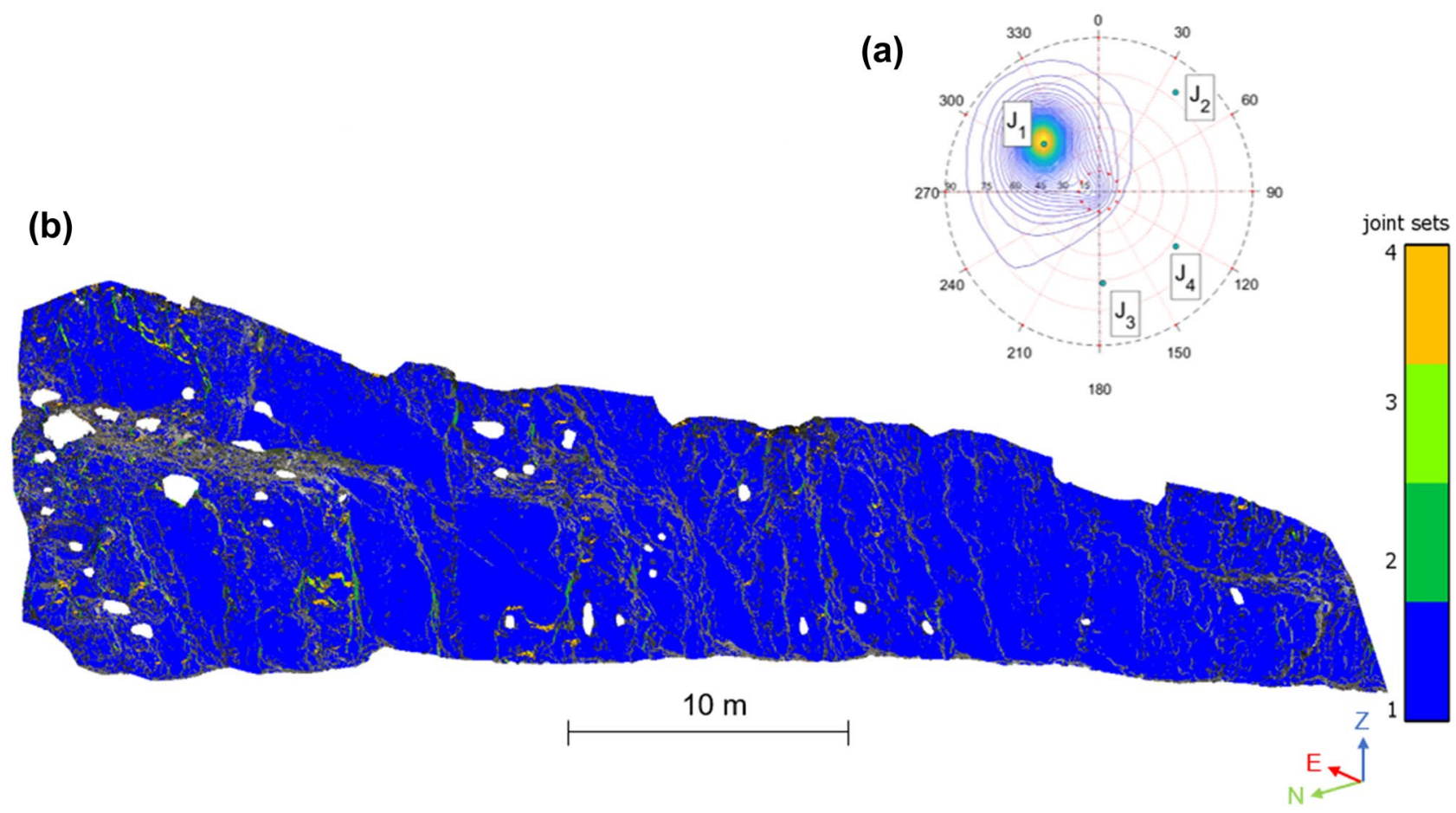

Fig. 7 (a) Extracted discontinuity sets as principal poles in stereogram plot. (b) The 3D point cloud classified into 4 discontinuity sets by the DSE software

surface of the slope was less than $15 \mathrm{~m}$ to obtain a sufficient level of detail of the geological structures.

A total of 236 RGB images were acquired and after a visual quality assessment, 221 were selected for image processing, discarding the low contrast and/or highly blurred ones. The photogrammetric software Pix4Dmapper version 4.3.31 was used to reconstruct the 3D model of the slope as a dense point cloud, using the standard processing parameters for the $3 \mathrm{D}$ model template. The generated point cloud contained $\sim 11$ million points, with ground sampling distance (GSD) of $5.26 \mathrm{~mm} /$ pixel, point spacing of less than $1 \mathrm{~cm}$, and an average point density of 22,278 points $/ \mathrm{m}^{3}$. The on-board satellite positioning system of the UAV provided a scaled, orientated, and georeferenced point cloud.
The points not belonging to the surface of the slope were removed using the CloudCompare software v. 2.10.2. Most of the dense vegetation was manually cropped out in the upper part of the slope but also some small bushes originating from inside the rock mass were deleted. This explains the empty areas without 3D points on the rocky slope surface. Points disconnected from the slope surface (i.e., in the air) were filtered out using the tool of Connected Components, applying octree level 9 (grid step $=0.101775)$ and a value of 5 for the minimum points per component. Finally, the area of interest was cropped to remove points belonging to the road in the bottom of the rocky slope and those belonging to soil and rock fragments in the surroundings. The final $3 \mathrm{D}$ point cloud contained 5,228,097 points (Fig. 6) and was converted to a.txt file for the discontinuity set characterization step.
Table 4 Discontinuity set dip direction and dip obtained via DSE software and compared to field data

\begin{tabular}{llcl}
\hline Discontinuity set & DSE & Field data & Difference \\
& Dip direction/dip $\left(^{\circ}\right)$ & Dip direction/dip $\left(^{\circ}\right)$ & Dip direction/dip $\left(^{\circ}\right)$ \\
\hline DS 1 & $311 / 51 \pm 30$ & $320 / 55 \pm 1$ & $9 / 4$ \\
DS 2 & $38 / 78 \pm 30$ & $24 / 85 \pm 1$ & $14 / 7$ \\
DS 3 & $178 / 62 \pm 30$ & $180 / 50 \pm 1$ & $2 / 12$ \\
DS 4 & $126 / 63 \pm 30$ & $119 / 61 \pm 1^{\mathrm{a}}$ & $7 / 2$ \\
\hline
\end{tabular}

${ }^{a}$ Manually obtained using the CloudCompare plugin Compass (Thiele et al. 2017) on the 3D point cloud of the rocky slope 
Table 5 Statistical analysis of normal spacing for the extracted discontinuity sets

\begin{tabular}{lllll}
\hline Spacing & DS 1 & DS 2 & DS 3 & DS 4 \\
\hline $\min (\mathrm{mm})$ & 0.05 & 3.88 & 9.39 & 1.02 \\
$\max (\mathrm{m})$ & 2.293 & 4.329 & 5.057 & 3.096 \\
mean $(\mathrm{m})$ & 0.311 & 0.481 & 0.620 & 0.514 \\
n cluster & 190 & 269 & 143 & 162 \\
n spacing values & 189 & 268 & 142 & 161 \\
\hline
\end{tabular}

\section{Discontinuity set characterization on the point cloud}

\section{Discontinuity set dip and dip direction}

The parameters used in the DSE software for the semiautomatic extraction of the discontinuity sets are summarized in Table 2. The results obtained for the dip and dip direction, the number of clusters for each set, and the total number of points assigned to each set are shown in Table 3.

Out of the 5,228,097 points, a total of $3,645,455$ were classified into discontinuity sets. The other 1,582,642 points remained unassigned since they do not fall into the cone filter criteria $\left(\gamma_{2} \leq 30^{\circ}\right)$; in other words, the poles of the normal vectors from those points have a dip and dip direction $>30^{\circ}$ to any of the discontinuity set poles.

Figure 7 summarizes visually the results obtained in this step with the stereogram plot of the extracted discontinuity set and the point cloud classified in different colors according to the discontinuity sets. DS 1 is the most representative discontinuity set in the slope with the majority of points. It corresponds to the slope surface and also to the bedding plane of the geological layers in the study site. DS 3 and DS 4 correspond to the overhangs, and DS 2 is almost a sub-vertical discontinuity bounding the lateral sides of the overhanging surfaces.

The discontinuity sets that are represented by planar surfaces are well characterized by this method and the points on these surfaces are correctly assigned to their corresponding discontinuity sets. However, points belonging to less planar surfaces (i.e., due to waviness or roughness) can be assigned to two different discontinuity sets as noted in some parts for DS 2 and DS 3. This limitation can explain why DS 2 has a slightly higher difference of $14^{\circ}$ in the dip direction and DS 3 of $12^{\circ}$ in dip compared to the values obtained in the field (Table 4). This discrepancy can be explained by the fact that the field measurements used for comparison were obtained locally on a chosen surface of the slope rather than the average of various measurements. For the scope of this work, the field measurements were only used to guide in the semi-automatic extraction in the DSE software, and further statistical analyses to evaluate the computed results for the discontinuity sets were not made. In-depth studies for the comparison or validation of the results obtained by the DSE software and field measurements are presented by Riquelme et al. (2014a), Jordá Bordehore et al. (2017), and Menegoni et al. (2019).

\section{Normal discontinuity spacing}

The normal spacing between discontinuities was calculated automatically using the DSE software (Table 5). For each cluster, the normal distance to the closest cluster is measured. The values of spacing, therefore, correspond to pairs of clusters. This implies that for each discontinuity
Fig. 8 Histogram of the computed normal spacing for each discontinuity set

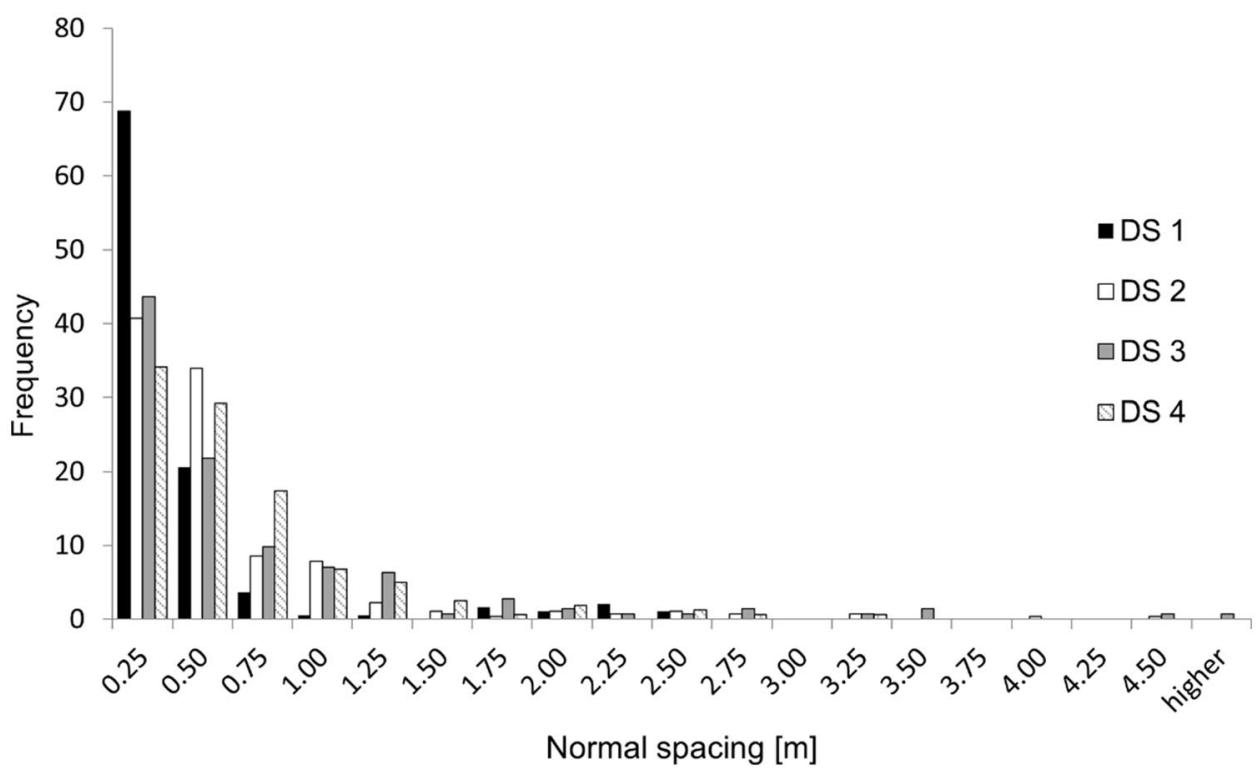


Table 6 Statistical analysis of persistence along the length of maximum chord for the extracted discontinuity sets

\begin{tabular}{lllll}
\hline Persistence & DS 1 & DS 2 & DS 3 & DS 4 \\
\hline $\min (\mathrm{m})$ & 0.11 & 0.15 & 0.14 & 0.16 \\
$\max (\mathrm{m})$ & 32.46 & 3.18 & 1.86 & 1.43 \\
mean (m) & 0.99 & 0.57 & 0.51 & 0.38 \\
mode (m) & 0.53 & 0.44 & 0.33 & 0.52 \\
n clusters & 190 & 269 & 143 & 162 \\
\hline
\end{tabular}

set, the total number of spacing values is equal to the total number of clusters minus 1 .

DS 3 and DS 4 have a higher mean normal spacing, whereas DS 1 has the lowest (Fig. 8). DS 1 represents the slope surface but also the bedding plane of the geological layers, and as a result, the mean spacing of this discontinuity set $(0.311 \mathrm{~m})$ represents on average the spacing between the bedding planes, which are corroborated by field observations as being of decametric order $(0.20$ to $0.30 \mathrm{~m})$. The extreme minimum spacing of DS 1 $(0.05 \mathrm{~mm})$ is due to the similar D parameter of clusters 5 and 11 , where the computation was performed. In other words, the clusters, in this case, are almost coplanar and therefore the normal distance is practically zero. If a $k$ threshold had been used $(k>0)$, these clusters would have been merged and only one merged cluster would have been formed.

The mean value of the normal spacing of each discontinuity set was considered as a geomechanical parameter for the $R M R_{b}$ computation ("Slope stability analysis" section).

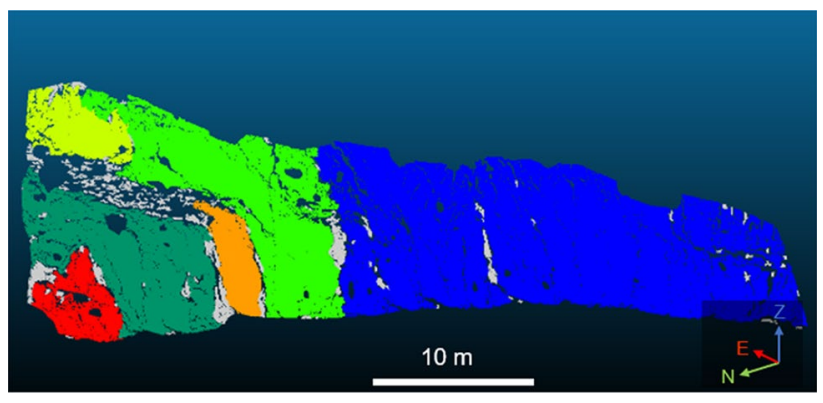

Fig. 10 Six major clusters of DS 1, randomly colorized

\section{Discontinuity persistence}

The persistence of each cluster of a given discontinuity set in the dip, dip direction, maximum length, and the area of the convex hull were computed in the DSE software, considering non-persistent discontinuity conditions $(k=0)$. As only the persistence along the length of the maximum chord was considered for the susceptibility assessment, the statistical analysis results are presented in Table 6 and histogram in Fig. 9. As expected, DS 1 has the maximum persistence value, since it represents the bedding plane. DS 2 and DS 3 have a similar range of mean persistence, whereas DS 4 has the lowest.

The mean value of the length of the maximum chord for DS 2, DS 3, and DS 4 was considered as a geomechanical parameter for the $R M R_{b}$ calculation ("Slope stability analysis" section). Since DS 1 is mainly represented by 6 major clusters out of 190 (Fig. 10), their mean value of maximum length was chosen $(15.35 \mathrm{~m})$ instead of
Fig. 9 Histogram of the computed persistence along the length of maximum chord for each discontinuity set

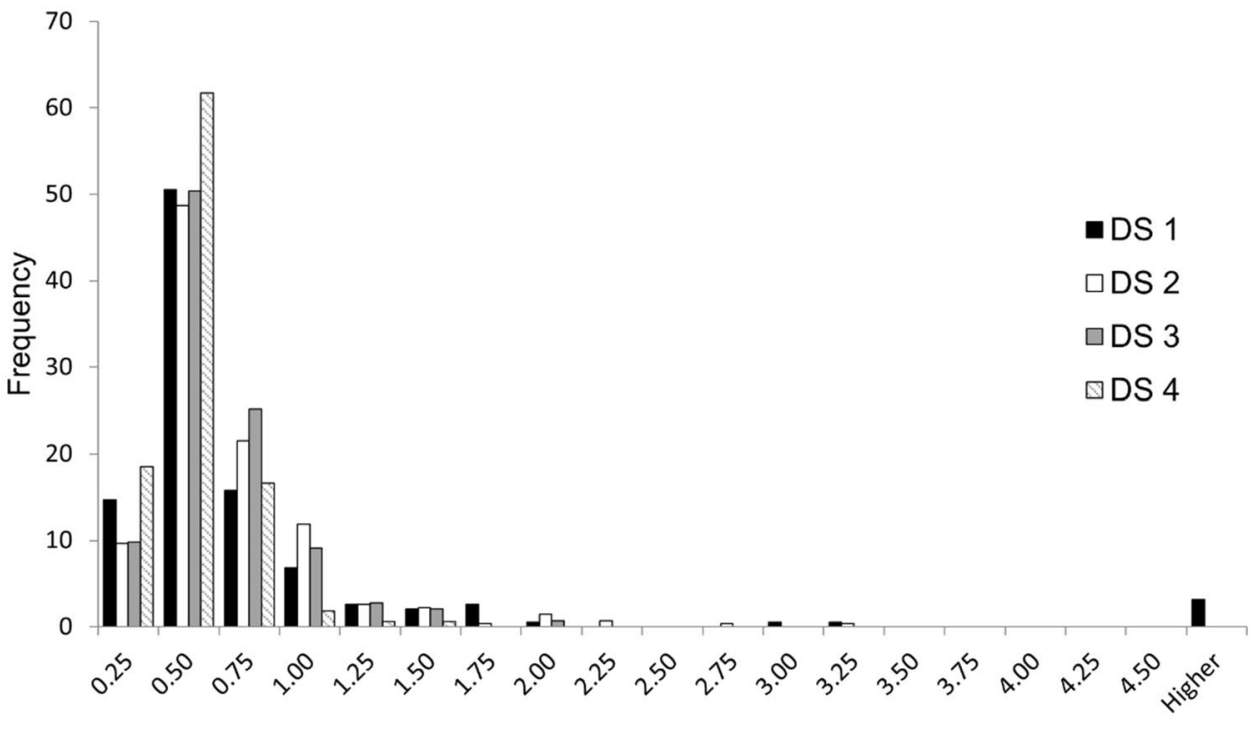

Persistence [m] 
Fig. 11 Sections in the 3D point cloud on the surface of the rocky slope (Fig. 6) used for RQD index calculation.

Only the segments with more than 100-mm length intersected by discontinuities (red) were considered
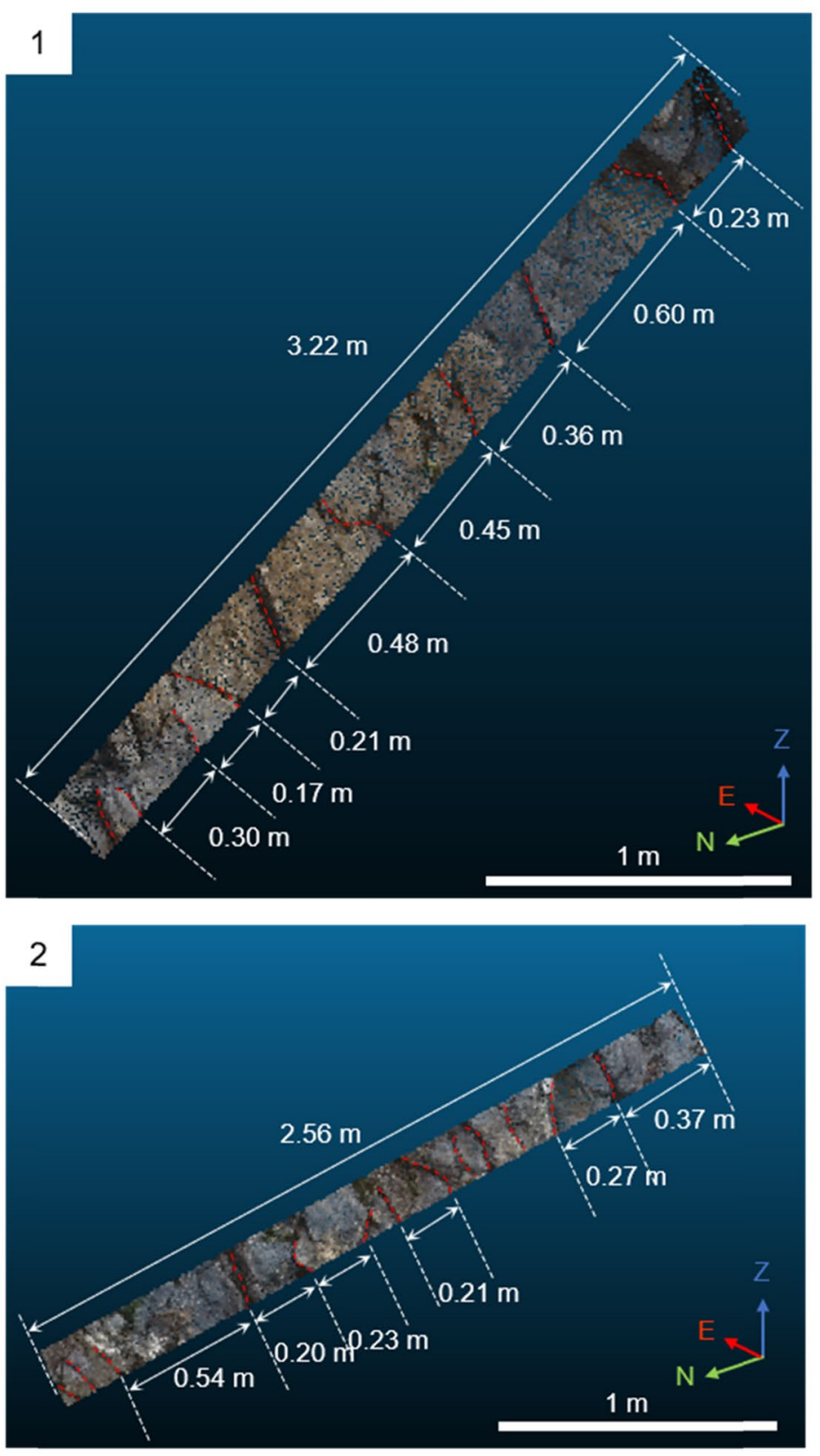

3

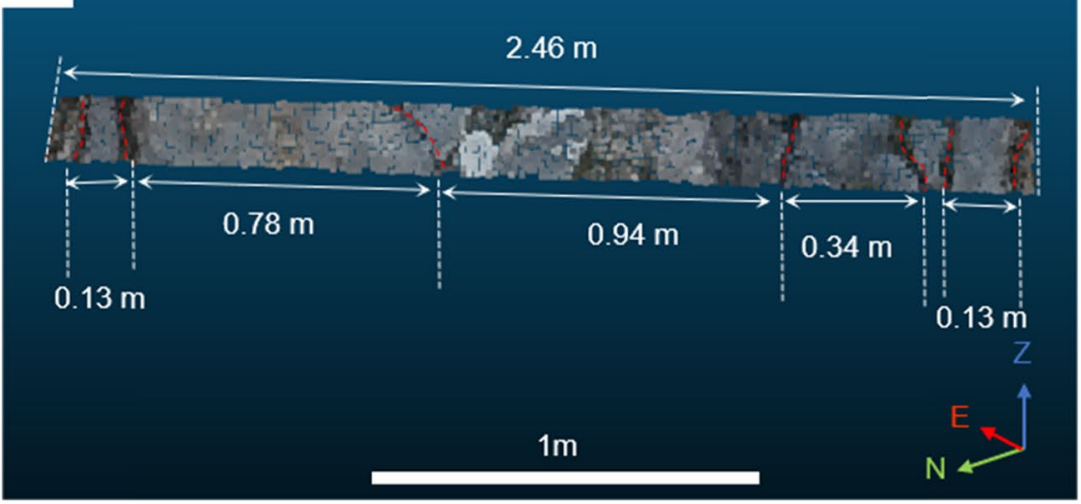


Table 7 Description of the five geomechanical parameters per discontinuity set used for $R M R_{b}$ computation

\begin{tabular}{|c|c|c|c|c|c|c|c|c|c|}
\hline \multirow[t]{2}{*}{ Sets } & \multirow{2}{*}{$\begin{array}{l}\mathrm{A} 1 \\
\mathrm{UCS}(\mathrm{MPa})\end{array}$} & \multirow{2}{*}{$\begin{array}{l}\mathrm{A} 2 \\
\mathrm{RQD}(\%)\end{array}$} & \multirow{2}{*}{$\begin{array}{l}\text { A3 } \\
\text { Spacing (m) }\end{array}$} & \multicolumn{5}{|c|}{ A4-conditions of discontinuity sets } & \multirow{2}{*}{$\begin{array}{l}\text { A5 } \\
\text { Groundwater }\end{array}$} \\
\hline & & & & Persistence (m) & Aperture (mm) & Roughness & Infilling & Weathering & \\
\hline DS1 & $50-100$ & 85 & 0.311 & 15.351 & $>5$ & Smooth & None & Unweathered & None \\
\hline DS2 & $50-100$ & 85 & 0.481 & 0.574 & $>5$ & Slightly rough & None & Unweathered & None \\
\hline DS3 & $50-100$ & 85 & 0.620 & 0.511 & $>5$ & Slightly rough & None & Unweathered & None \\
\hline DS4 & $50-100$ & 85 & 0.514 & 0.378 & $>5$ & Slightly rough & None & Unweathered & None \\
\hline
\end{tabular}

the mean value considering all the 190 clusters together $(0.99 \mathrm{~m})$.

\section{Slope stability analysis}

For the computation of the $R M R_{b}$, the geomechanical parameters were characterized by field observations (e.g., Uniaxial Compressive strength-UCS, weathering, groundwater) and scanlines (aperture, roughness, infilling), observations on the images (infilling), and on the 3D point cloud (RQD, spacing, persistence, aperture). The estimated UCS value of 50-100 MPa was obtained by using a geologic hammer to fracture specimens (limestone) and counting the required blows to break them (ISRM 1978), yielding from 2 to 5 blows.

For the RQD index calculation, three sections were selected on the RGB 3D point cloud (Fig. 6), along a profile oriented perpendicularly to the principal discontinuity set on the surface of the slope. The calculation of the RQD index followed the same procedure as for drill cores (Fig. 11) and yielded $88 \%$ for section $1,72 \%$ for section 2 , and $95 \%$ for section 3 , resulting an average of $85 \%$. To validate this approach, the mean normal discontinuity set spacing obtained using the DSE software (Table 5) was used in Eq. 2, providing $J_{V}=8.72$ discontinuities $/ \mathrm{m}^{3}$. This value of the $J_{V}$ applied to Eq. 1 provided a RQD index of $88 \%$, close to the average value obtained by our approach $(85 \%)$.

The aperture of 9 out of 10 discontinuities which intersected the scanline presented a value greater than $5 \mathrm{~mm}$, as well as the majority of the apertures in other areas of the rocky slope. For the roughness characterization, the only discontinuity set that presented a uniform description is DS 1 , which was characterized as smooth. The other discontinuity sets presented variable roughness either in macro-scale (stepped, undulating, and planar) or microscale (rough, smooth), according to the definition by ISRM (1978) or considering the ranges of Joint Roughness Coefficient-JRC values (from 2 to 10,14-16, and 18-20) according to the definition by Barton and Choubey (1977). Therefore, the intermediate description of slightly rough was chosen for DS 2, 3, and 4 for calculation of the $R M R_{b}$.

The infilling was absent and no pronounced weathering was observed in any discontinuity neither the presence of groundwater in the rocky slope. The description of the five geomechanical parameters for the $R M R_{b}$ computation for each discontinuity set is presented in Table 7 and the corresponding rating in Table 8. Although the score of each discontinuity set is slightly different (63-75), all scores fall within the same class II of the rock mass, corresponding to good quality rock.

The input parameters for the SMR index computation and the results for each discontinuity set applying the SMRTool calculator are shown in Table 9. Although potential toppling failures were identified in the SMRTool, they were not considered for this case study since the visual inspection of the rocky slope did not show important evidence of these types of failures. The large extension of the bedding plane (being fully persistent) is where the majority of discontinuities terminate, preventing the discontinuities to penetrate further on the rock mass and creating the typical parallelepiped shaped blocks with sufficient height to form a toppling failure mechanism.

DS 2 and DS 3 were assigned with an SMR corresponding to class I (completely stable), DS 4 to class II (stable), and DS 1 to class III (partially stable). DS 1 configures a more unsafe situation compared to others because its orientation is parallel to the slope orientation, indicated by $F_{1}=1$. In other words, the bedding plane of the geologic layer has the same dip direction and angle as the sliding plane of the slope,
Table 8 Rating of geomechanical parameters and $R M R_{\mathrm{b}}$ for each discontinuity set

\begin{tabular}{|c|c|c|c|c|c|c|c|c|c|c|c|}
\hline \multirow[t]{2}{*}{ Sets } & \multirow[t]{2}{*}{ A1 } & \multirow[t]{2}{*}{$\mathrm{A} 2$} & \multirow[t]{2}{*}{ A3 } & \multicolumn{6}{|c|}{ A4-conditions of discontinuity sets } & \multicolumn{2}{|l|}{$R M R_{b}$} \\
\hline & & & & & & & & & & Rating & Class \\
\hline DS 1 & 7 & 17 & 10 & 1 & 0 & 1 & 6 & 6 & 15 & 63 & II \\
\hline DS 2 & 7 & 17 & 10 & 6 & 0 & 3 & 6 & 6 & 15 & 70 & II \\
\hline DS 3 & 7 & 17 & 15 & 6 & 0 & 3 & 6 & 6 & 15 & 75 & II \\
\hline DS 4 & 7 & 17 & 10 & 6 & 0 & 3 & 6 & 6 & 15 & 70 & II \\
\hline
\end{tabular}


Table 9 Parameters for SMR computation and results for each discontinuity set

\begin{tabular}{lllllllllllllll}
\hline Sets & $\begin{array}{l}\text { Dip } \\
\text { direc- } \\
\text { tion }\left(^{\circ}\right)\end{array}$ & Dip $\left(^{\circ}\right)$ & $R M R_{b}$ & $\mathrm{~A}\left({ }^{\circ}\right)$ & $\mathrm{B}\left(^{\circ}\right)$ & $\mathrm{C}^{\circ}\left({ }^{\circ}\right)$ & Failure $^{\mathrm{a}}$ & $\mathrm{F}_{1}$ & $\mathrm{~F}_{2}$ & $\mathrm{~F}_{3}$ & $\mathrm{~F}_{4}$ & SMR & Class \\
\hline DS 1 & 311 & 51 & 63 & 0 & 51 & 0 & $\mathrm{P}$ & 1 & 1 & -25 & 15 & 53 & $\mathrm{III}$ \\
DS 2 & 38 & 78 & 70 & 87 & 78 & 27 & $\mathrm{P}$ & 0.15 & 1 & 0 & 15 & 85 & $\mathrm{I}$ \\
DS 3 & 178 & 62 & 75 & 47 & 62 & 113 & $\mathrm{~T}$ & 0.15 & 1 & -6 & 15 & 89 & $\mathrm{I}$ \\
DS 4 & 126 & 63 & 70 & 5 & 63 & 114 & $\mathrm{~T}$ & 0.85 & 1 & -6 & 15 & 80 & $\mathrm{II}$ \\
\hline
\end{tabular}

${ }^{\text {a }} P$ planar failure, $T$ toppling failure which favors instability. It is worth noticing that DS 3 that represents overhanging configures a safer situation compared to DS 1 , but only in terms of failure mechanism. This can be explained because DS 3 is not parallel to the slope orientation but rather perpendicular to it. However, this discontinuity set as well as DS 4 are tension cracks or overhangs and contribute to instability due to lack of support in the rock mass. In these areas, the detached blocks slide on the slope surface, indicating the potential occurrence of instabilities. Therefore, these discontinuity sets will be also considered as indicators (overhangs) in the susceptibility analysis.

\section{Rockfall susceptibility assessment}

\section{Indicators}

The results of each indicator used for the rockfall susceptibility assessment $\left(I_{S}\right.$-spacing, $I_{P}$-persistence, $\mathrm{I}_{S M R}-$ Slope

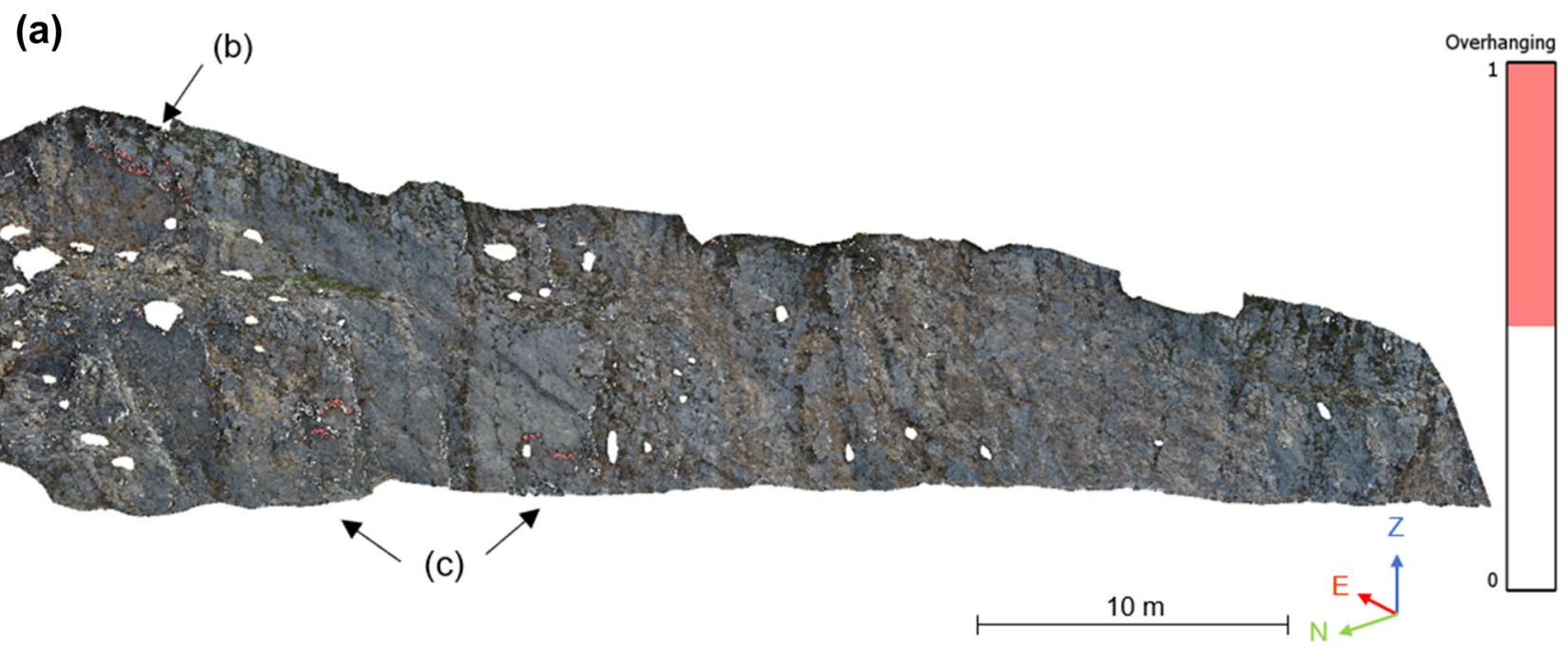

(b)

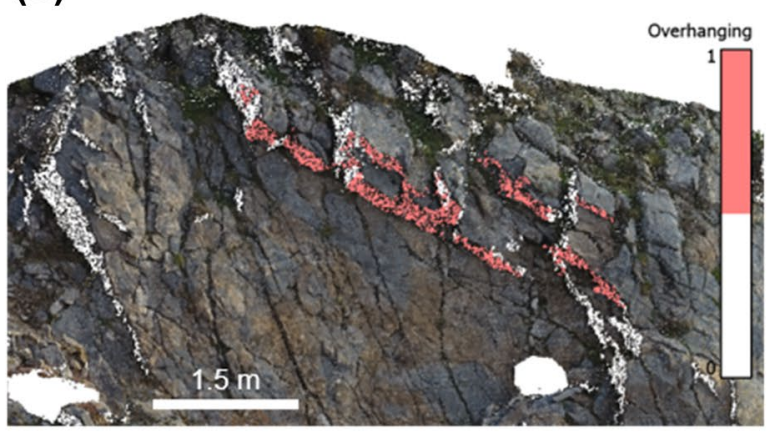

(c)

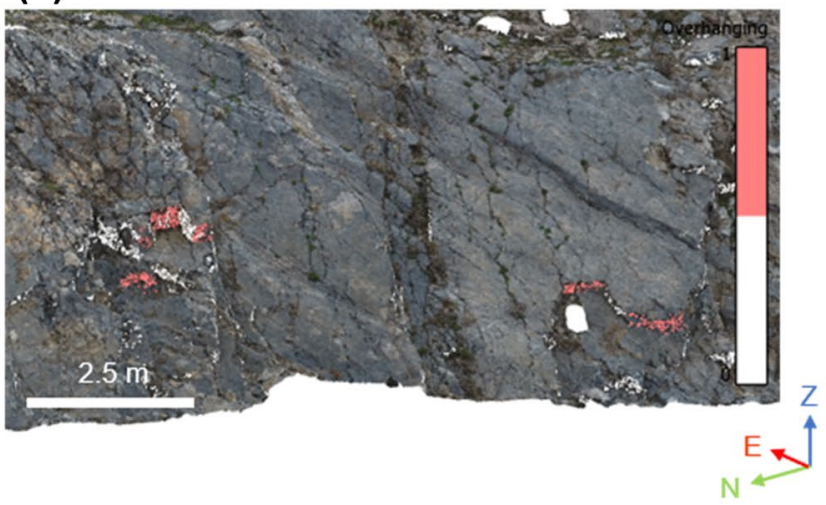

Fig. 12 (a) RGB point cloud overlaid with overhanging surfaces (red-1) compared to non-overhanging surfaces (white-0). Closer view of the upper overhang (b) and the two lower overhang (c) areas in pink (1) 

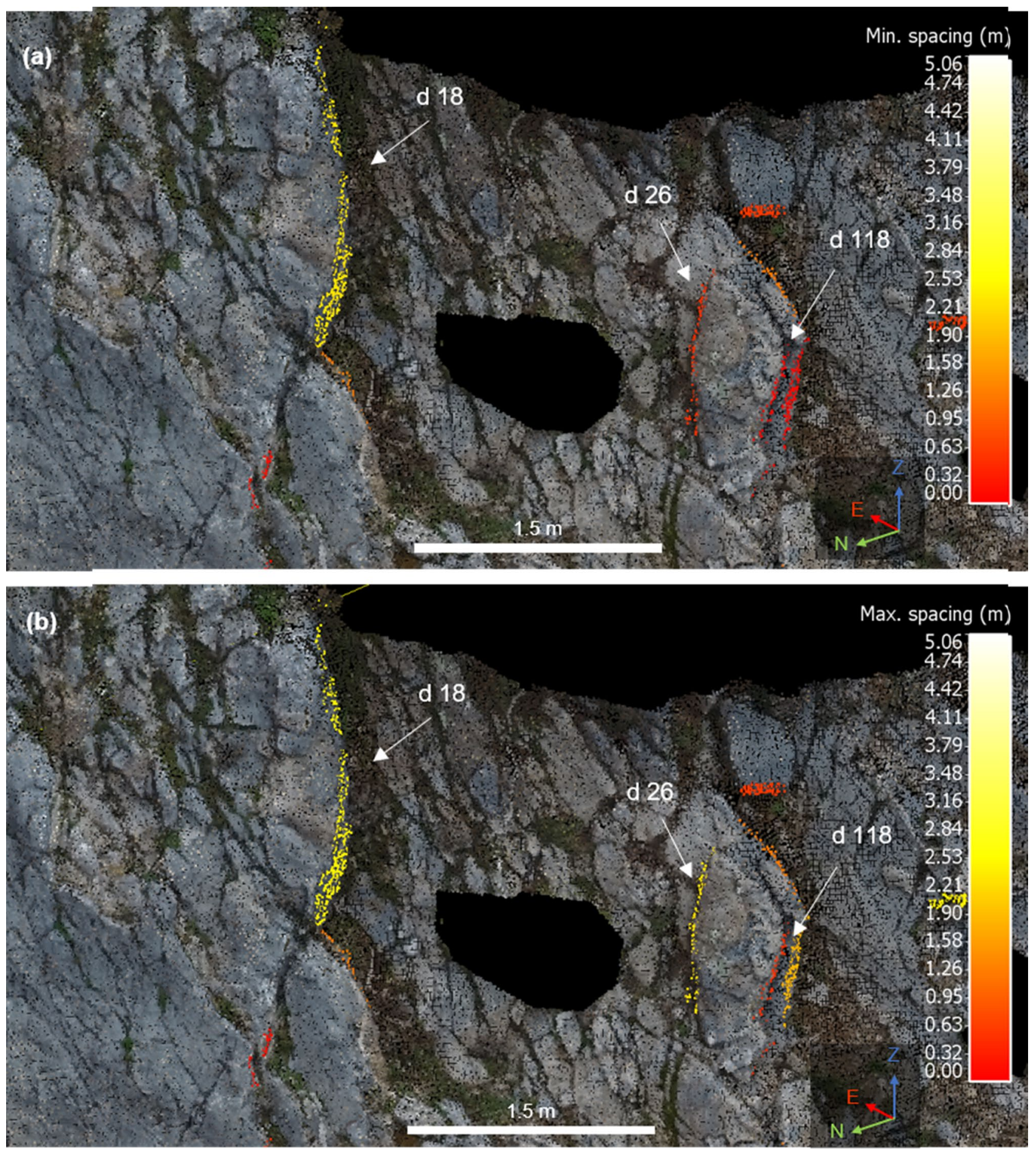

Fig. 13 Relationship of neighboring discontinuities 18 (d18) and 118 (d118) with discontinuity 26 (d 26). (a) The 3D points of d26 with a value of $0.48 \mathrm{~m}$ considering the normal spacing to $\mathrm{d} 118$ (minimum spacing). (b) The 3D points of d26 with a value of $2.26 \mathrm{~m}$ considering the normal spacing to $\mathrm{d} 18$ (maximum spacing)

discontinuities extracted by the DSE software were used for this analysis except those belonging to DS 1 . The reason is that these discontinuities are the most dominant in the slope and represent the sliding plane (Fig. 7), as the platy 

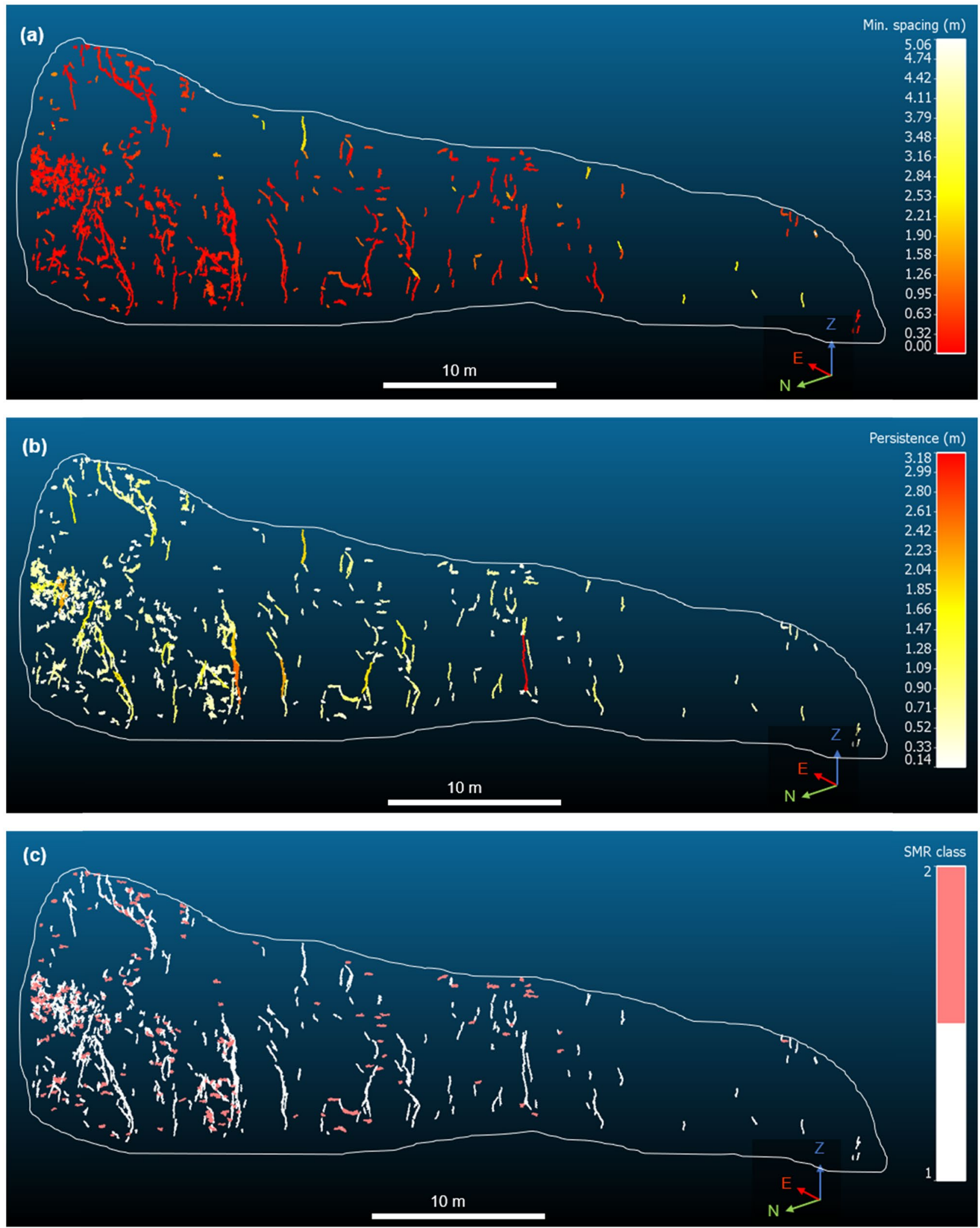

Fig. 14 Rock slope outlined and discontinuities surface colorized by the minimum normal spacing (a), maximum persistence (b), and SMR index (c). For spacing and persistence, reddish values indicate higher susceptibility spots for rockfall, whereas for SMR index are the discontinuities in pink (class II) 

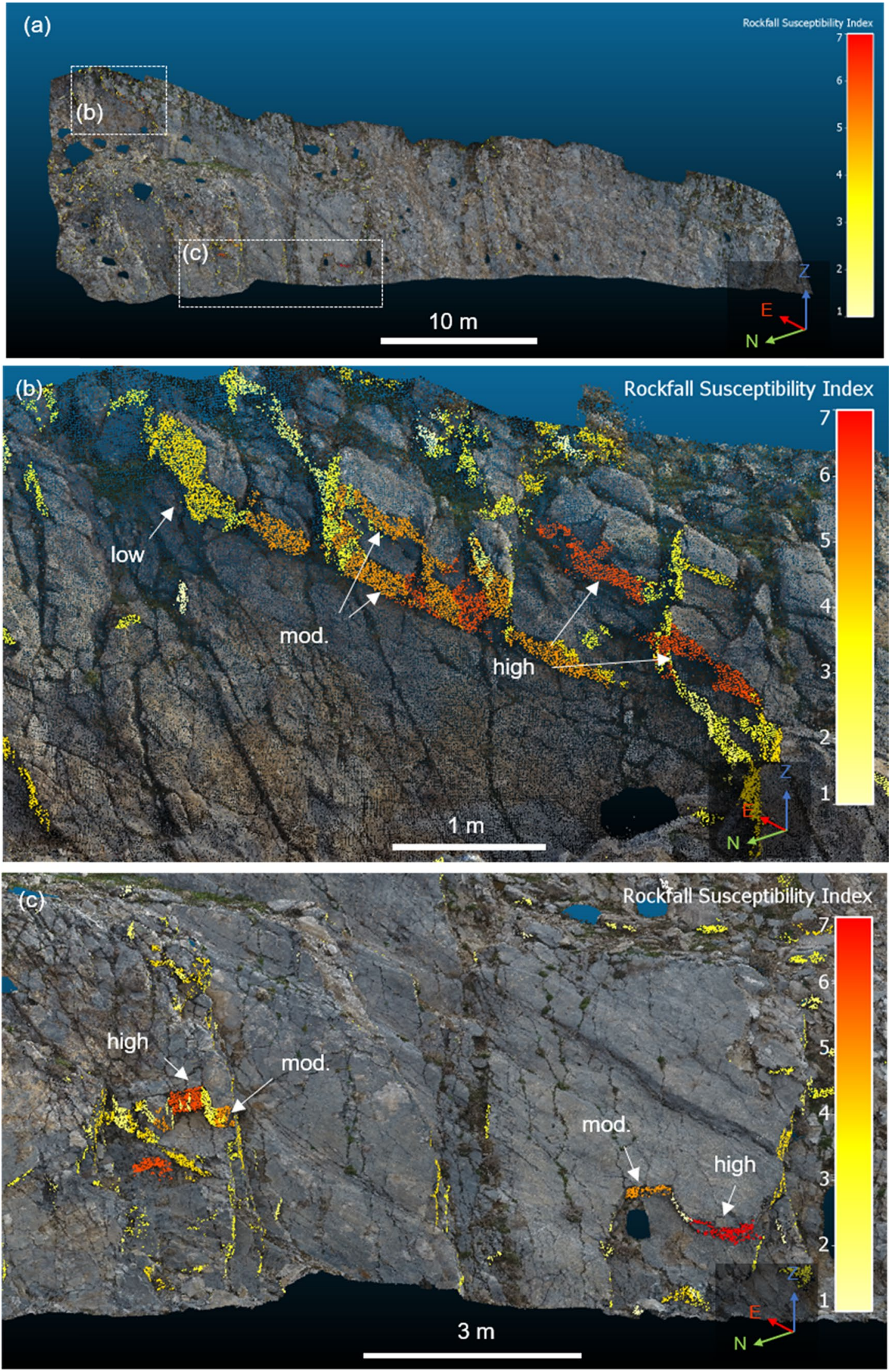
४Fig. 15 (a) Areas with moderate (3-5) and high (5-7) rockfall susceptibility index are mainly in the left part of the slope. Overhanging areas in the upper (b) and bottom (c), differentiated in terms of susceptibility due to spacing and persistence properties

limestone detaches in platy layers. Thus, given that majority of the slope consists of sliding planes, the entire slope would result as unstable, not being useful to distinguish different susceptibility levels. The presence of overhangs however is a differential factor determining the falling of blocks. It means that the lack of support plays a major role in rock detachment for this particular case study. Wherever the slope surface profile is not parallel with the sliding planes it would be useful to include all the discontinuities.

For $I_{o}$, three areas with overhanging surfaces were identified on the left side of the rocky slope (Fig. 12): one in the upper part, almost above the height of $14 \mathrm{~m}$ (Fig. 12b), and two close to the bottom below the height of $3 \mathrm{~m}$ (Fig. 12c). The surfaces of the overhangs are well delineated in most of the cases, except for less flat surfaces as shown in few parts in the bottom. The discontinuity sets which contain overhanging discontinuities are the DS 3 with 11 discontinuities and the DS 4 with 9 discontinuities.

To account for a conservative scenario for the $I_{S}$, the minimum normal spacing was considered whenever a discontinuity presented more than one value. Figure 13 shows a realistic example for discontinuity 26 of DS 2 . The DSE software computed the normal spacing to discontinuity 118 on its right side $\left(S_{26-118}=0.48 \mathrm{~m}\right)$ and to discontinuity 18 on the left side $\left(S_{26-18}=2.26 \mathrm{~m}\right)$. The use of the minimum spacing for the discontinuity $26\left(S_{26-118}\right)$ leads to a poorer rock mass quality (Fig. 13a) whereas the use of maximum spacing $\left(S_{26-18}\right)$ leads to a higher rock mass quality (Fig. 13b).
After applying the minimum normal spacing for each discontinuity for DS 2 , DS 3 , and DS 4 , the $I_{S}$ in a $3 \mathrm{D}$ space is obtained (Fig. 14a). The majority of the discontinuity sets with minimum normal spacing are located on the left part of the rock slope (bottom and top). Few discontinuities have a higher value of spacing greater than $2 \mathrm{~m}$ (yellowish in Fig. 14a) and are located in the central and right parts of the rock slope. To account for a conservative scenario for the $I_{P}$, the maximum length of persistence computed by the DSE software was assigned to each discontinuity of DS 2, DS 3 , and DS 4 (Fig. 14b). In comparison with the 3D spacing distribution, the discontinuities with higher persistence are in the central area of the slope. The rocky slope has SMR classes I (DS 2, DS 3) and II (DS 4) located mainly on the left part (Fig. 14c).

\section{Rockfall susceptibility index}

The indicators for rockfall susceptibility were scored based on the thresholds of Table 1 and summed up to provide the rockfall susceptibility index $I_{R F}$ Eq. (3). It is worth noticing that the SMR classes VI (unstable) and V (completely unstable) were not present in the rocky slope (Table 9) and thus the higher value of $I_{R F}$ is 7 instead of 8 . Nevertheless, the proposed scoring of the $I_{S M R}$ allows a broader applicability of this methodology in rocky slopes where all the SMR classes are present.

The 3D visualization of the $I_{R F}$ indicates areas of higher susceptibility in the left part of the rocky slope (Fig. 15a). The areas of overhangs (bottom and upper part) show moderate to high susceptibility depending on the persistence and spacing of discontinuities (Fig. 15b, c). The persistence of the exposed surfaces is a useful indicator since it contributes

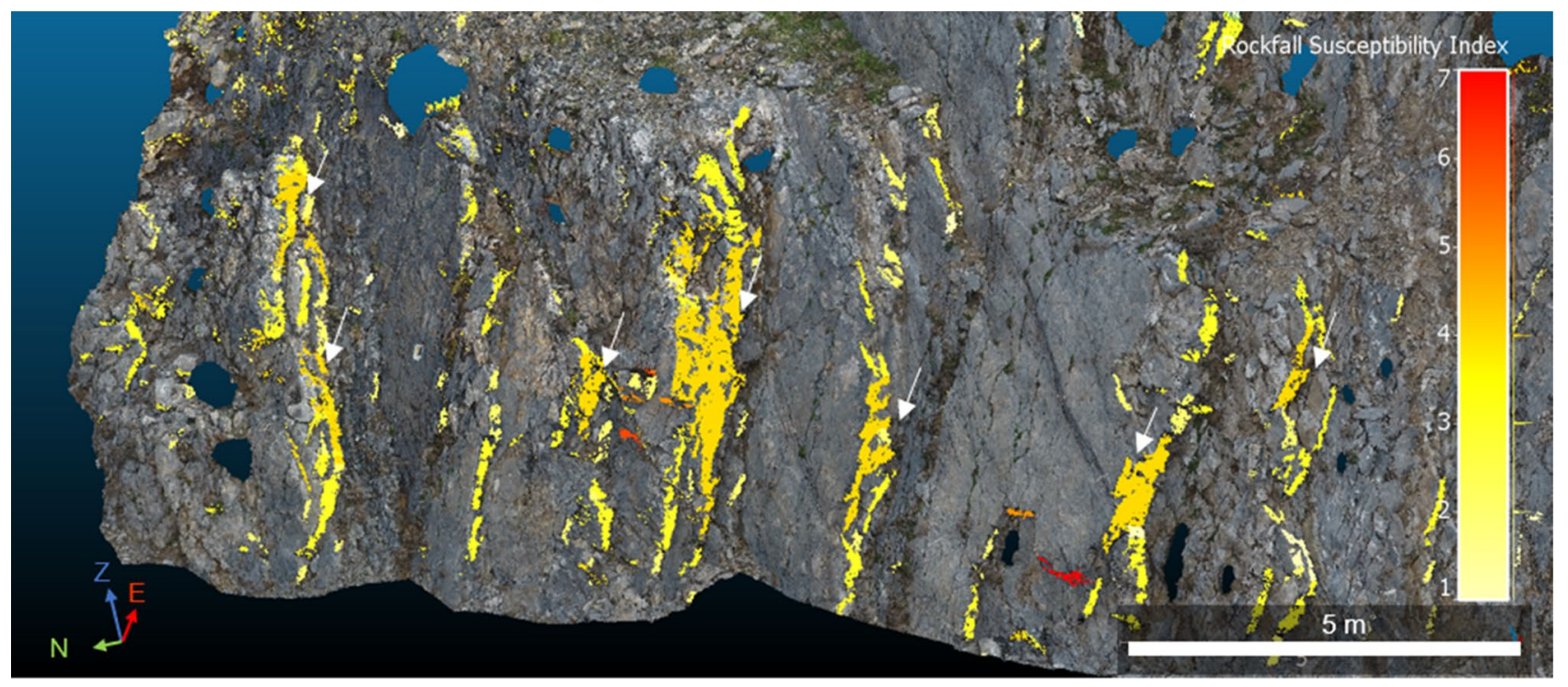

Fig. 16 Moderate susceptibility areas in dark yellow as lateral exposed surfaces of the rocky slope 


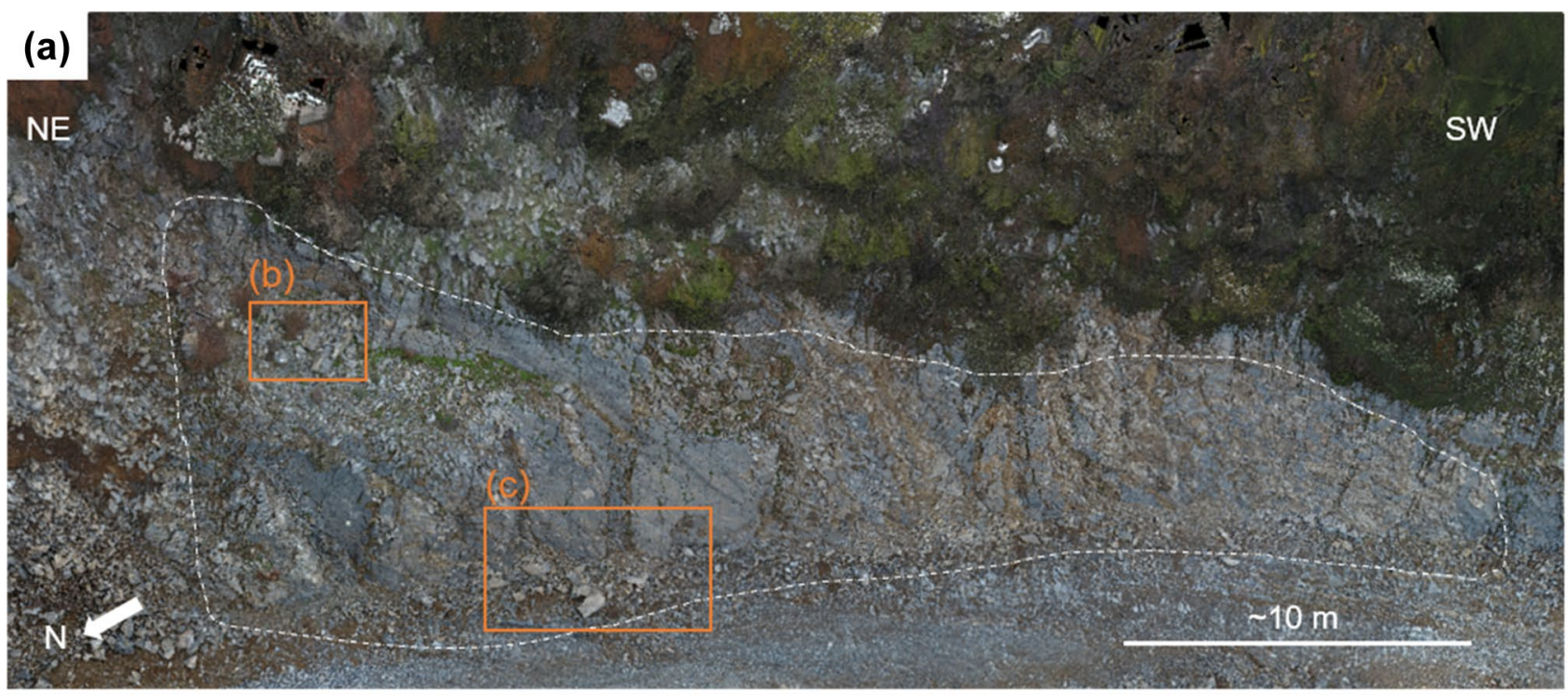

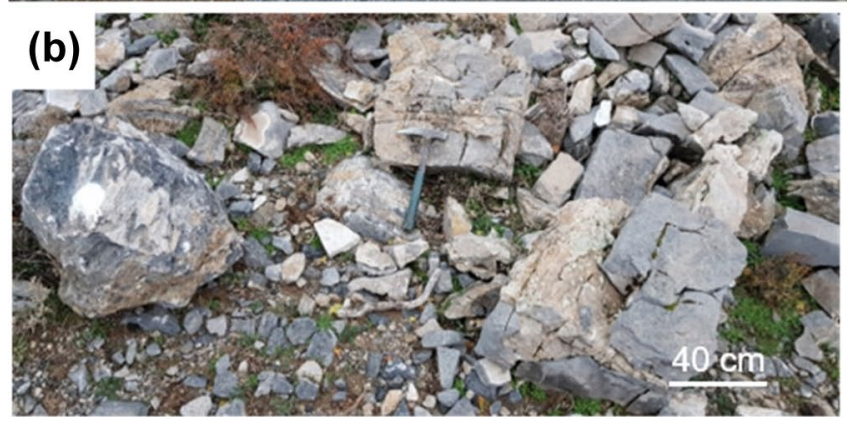

Fig. 17 (a) Orthoimage of the rock slope (white dashed line) generated with the UAV photos and the locations where bigger and more fallen blocks were found (orange boxes). (b) Closer view of the fallen

to the differentiation of susceptibility levels within the overhanging areas. In other words, the greater the extension of lack of support is (persistence of overhangs), the more prone to rockfall it will be compared to smaller areas, an indication of larger unstable volumes.

In the lateral view of the 3D rocky slope, there are several areas with moderate susceptibility represented by the discontinuities with higher persistence (Fig. 16), showing previous breakages of rocks that were once part of the continuous slope surface. This inference is based on the observation of the right part of the slope, where fewer lateral exposed surfaces are present, and as a consequence, the slope surface is more continuous.

\section{Discussion}

The validation of the rockfall susceptibility assessment was carried out qualitatively by visual inspection from field observation and images (Fig. 17). The areas of high and moderate susceptibility, according to the $I_{R F}$ score, correspond to the areas where bigger and more fallen blocks are

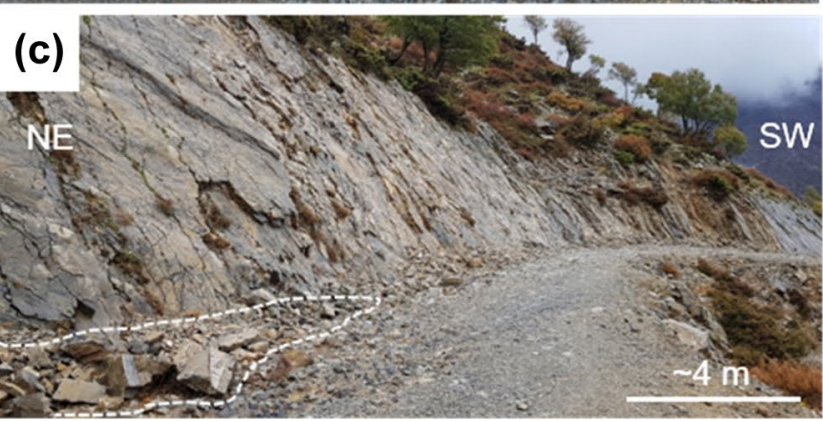

blocks below overhanging surfaces. (c) Closer view of the bigger blocks located on the foot of the slope

observed, i.e., below the overhanging surfaces (Fig. 17b) and the bottom left of the foot of the slope (Fig. 17c). In contrast, the right and continuous part of the slope has fewer and smaller blocks compared to the left part. Thus, the approach proposed in this work for identifying rockfall source areas yields realistic results. Further quantitative and more accurate validation can be performed at a later stage, using change detection techniques to assess future rockfalls and compare their location with the detected sources.

The proposed methodology can be adapted for its application to other study areas in terms of the use and assessment of indicators, scoring, and integration into the proposed $I_{R F}$. For instance, even though the studied rocky slope did not have SMR class VI and V, it was included in the scoring of indicators (lower susceptibility). Although the studied rocky slope only presented planar failures, the other types (toppling and wedge) are partly incorporated into SMR and thus could be applied to slopes where these failures occur.

Adaptations required for the transferability of this methodology lie in the scoring of the indicators based on the thresholds for the $I_{S}$ and $I_{P}$ in areas of low (0), moderate (1), or high susceptibility (2), which are indeed site-specific. However, 
the higher weighting for longer persistence, small normal spacing discontinuities, presence of overhangs, and SMR classes VI and V should remain. One relevant note when using this approach elsewhere is that the identified areas of higher susceptibility do not guarantee that a rock detachment will occur, but rather that is it more likely compared to other areas of the same rocky slope based on referred indicators only. The study of the triggering mechanisms is not part of this work.

Concerning the intrinsic characteristics of the chosen slope, it is worth noticing that the most dominant discontinuity set (DS 1) has the majority of the indicators contributing to a higher rockfall susceptibility: (i) it is parallel to the slope which configures the worst-case scenario for planar failure computed by the SMR index, (ii) has the highest persistence (Table 6), and (iii) the minimum spacing (Table 5). For these reasons, almost the entire slope would be classified as highly susceptible whereas, in reality, only specific parts are, i.e., overhangs and lateral exposed surfaces (Fig. 16). Validation is required for rocky slopes with different discontinuity set characteristics to evaluate its performance.

This methodology has the advantage that the original 3D point cloud is used from beginning to end as new information of indicators is added as a scalar field, without the need for mesh generation and thus interpolation of results. The spacing and persistence indicators $\left(I_{S}\right.$ and $\left.I_{P}\right)$ consider the local information of each cluster (discontinuity). A limitation of this work is that discontinuities represented by trace lengths are not used for the computation of the persistence and the spacing, and thus not incorporated as indicators for the susceptibility analysis.

\section{Conclusions}

This work presents a novel methodology for Rockfall Susceptibility Assessment for 3D slope models in the form of point clouds. It consists of four steps: (i) 3D slope model reconstruction using UAV digital photogrammetry, (ii) automatic characterization of discontinuity sets, (iii) slope stability analysis, and (iv) susceptibility assessment using a new Rockfall Susceptibility Index. The proposed approach can be used to refine the identification of potential rockfall source areas and to improve the input for hazard assessment, including rockfall run-out simulations. The methodology was applied to a rocky slope in the mountainous area of the Samaria National Park, in Crete Island, Greece. The identified areas of higher and moderate rockfall susceptibility in the $3 \mathrm{D}$ point cloud correspond to the areas where the bigger and highest number of fallen blocks were found on the foot of the slope, indicating that the methodology is efficient for detecting automatically potential rockfall sources.
The methodological workflow proposed in this work uses the original 3D point cloud from beginning to end as new information of indicators for susceptibility is added. This brings the advantage of no mesh generation and interpolation, which could compromise the quality of the 3D model. Moreover, the proposed methodological workflow can be automatized to be an efficient tool for rockfall source detection. Most of the input data needed to generate the rockfall susceptibility index are derived directly from the 3D point cloud, including the alternative approach to estimate the RQD index herein proposed and validated by the correlation to volumetric joint count $J_{V}$ of Palmstrom (2005). The only additional source of data is fieldwork data or image analysis to complement the discontinuity characterization (i.e., aperture, roughness, infilling, weathering, and groundwater).

This work also provides an attempt to visualize normal spacing, persistence, and the SMR index information in a point cloud environment. Additional innovation relates to the incorporation of the extension of overhangs in the rockfall susceptibility assessment by considering the persistence of exposed surface as maximum length. For the overhanging areas, this procedure allows the differentiation of parts with a larger lack of support them others, and as a consequence an indication of a greater volume of rock that is prone to rockfall. Further work should focus on the validation of this methodology in rocky slopes with different characteristics in terms of discontinuity set configuration (i.e., dominant discontinuity set not parallel to slope surface), or in the case that different SMR classes are present (I to VI), and where toppling and wedge failure mechanism occurs.

Acknowledgements This study was developed in the context of the MSc research of the first author, funded by the Excellence Scholarship Program of the Faculty of Geo-information Science and Earth Observation, University of Twente, the Netherlands. The authors gratefully acknowledge the personnel and president, Petros Lymberakis, of the Management Body of Samaria - West Crete, and the Forest Directorate of Chania for the logistic support and permissions for the fieldwork activities in the area. The second author additionally acknowledges the projects "Advances in rockfall quantitative risk analysis incorporating developments in geomatics-GeoRisk" (reference code: PID2019-103974RB-I00/AEI/10.13039/501100011033) and "Characterization and modeling of rockfalls-RockModels" (reference code: BIA2016-75668-P) funded by the Spanish Ministry of Economy and Competitiveness, and co-funded by the Agencia Estatal de Investigación (AEI) and, the latter, by The European Regional Development Fund (ERDF or FEDER in Spanish), within the framework of the State Plan of Scientific-Technical Research and Innovation. Finally, the authors acknowledge the editorial board member and reviewers of this journal for the comments and suggestions that significantly contributed for the quality of this publication.

Author contribution Conceptualization: D. S. N. A. Albarelli and O. C. Mavrouli; methodology: D. S. N. A. Albarelli and O. C. Mavrouli; validation: D. S. N. A. Albarelli and O. C. Mavrouli; formal analysis: D. S. N. A. Albarelli and O. C. Mavrouli; investigation: D. S. N. A. Albarelli, O. C. Mavrouli, and P. Nyktas; resources: P. Nyktas; writing-original draft, D. S. N. A. Albarelli; writing-review and editing: D. S. N. A. 
Albarelli, O. C. Mavrouli, and P. Nyktas; visualization: D. S. N. A. Albarelli; supervision: O. C. Mavrouli; project administration: O. C. Mavrouli; funding acquisition: D. S. N. A. Albarelli and O. C. Mavrouli.

Funding Funding was provided by the Excellence Scholarship Program of the Faculty of Geo-information Science and Earth Observation, University of Twente, the Netherlands.

\section{Declarations}

Conflict of interest The authors declare no competing interests.

Open Access This article is licensed under a Creative Commons Attribution 4.0 International License, which permits use, sharing, adaptation, distribution and reproduction in any medium or format, as long as you give appropriate credit to the original author(s) and the source, provide a link to the Creative Commons licence, and indicate if changes were made. The images or other third party material in this article are included in the article's Creative Commons licence, unless indicated otherwise in a credit line to the material. If material is not included in the article's Creative Commons licence and your intended use is not permitted by statutory regulation or exceeds the permitted use, you will need to obtain permission directly from the copyright holder. To view a copy of this licence, visit http://creativecommons.org/licenses/by/4.0/.

\section{References}

Abellán A, Vilaplana JM, Martínez J (2006) Application of a longrange terrestrial laser scanner to a detailed rockfall study at Vall de Núria (Eastern Pyrenees, Spain). Eng Geol 88:136-148. https:// doi.org/10.1016/j.enggeo.2006.09.012

Abellán A, Derron MH, Jaboyedoff M (2016) "Use of 3D point clouds in geohazards" special issue: current challenges and future trends. Remote Sens 8:1-9. https://doi.org/10.3390/rs8020130

Abellán A, Oppikofer T, Jaboyedoff M, Rosser NJ, Lim M, Lato MJ (2014) Terrestrial laser scanning of rock slope instabilities. Earth Surface Process Landf 39:80-97. https://doi.org/10.1002/esp.3493

Alameda-Hernández P, El Hamdouni R, Irigaray C, Chacón J (2019) Weak foliated rock slope stability analysis with ultra-close-range terrestrial digital photogrammetry. Bull Eng Geol Env 78:11571171. https://doi.org/10.1007/s10064-017-1119-z

Andrea F, Andrea G, Giuseppe M (2010) Rock slopes failure susceptibility analysis: from remote sensing measurements to geographic information system raster modules. Am J Environ Sci 6:489-494. https://doi.org/10.3844/ajessp.2010.489.494

Assali P, Grussenmeyer P, Villemin T, Pollet N, Viguier F (2016) Solid images for geostructural mapping and key block modeling of rock discontinuities. Comput Geosci 89:21-31. https://doi.org/ 10.1016/j.cageo.2016.01.002

Baillifard F, Jaboyedoff M, Sartori M (2003) Rockfall hazard mapping along a mountainous road in Switzerland using a GIS-based parameter rating approach. Nat Hazard 3:431-438. https://doi.org/ 10.5194/nhess-3-435-2003

Barton N, Choubey V (1977) The shear strength of rock joints in theory and practice. Rock Mech Rock Eng 10:1-54. https://doi.org/10. 1007/BF01261801

Bieniawski ZT (1989) Engineering rock mass classifications: a complete manual for engineers and geologists in mining, civil, and petroleum engineering. Wiley, New York

Bonilla-Sierra V, Scholtès L, Donzé FV, Elmouttie MK (2015) Rock slope stability analysis using photogrammetric data and DFN-
DEM modelling. Acta Geotech 10:497-511. https://doi.org/10. 1007/s11440-015-0374-z

Bonneau D, DiFrancesco PM, Hutchinson DJ (2019) Surface reconstruction for three-dimensional rockfall volumetric analysis. ISPRS Int J Geo Inf 8:1-19. https://doi.org/10.3390/ijgi8120548

Buyer A, Aichinger S, Schubert W (2020) Applying photogrammetry and semi-automated joint mapping for rock mass characterization. Eng Geol 264:1-9. https://doi.org/10.1016/j.enggeo.2019.105332

Chen N, Kemeny J, Jiang Q, Pan Z (2017) Automatic extraction of blocks from 3D point clouds of fractured rock. Comput Geosci 109:149-161. https://doi.org/10.1016/j.cageo.2017.08.013

CloudCompare (version 2.10) [GPL software] (2020) http://www. cloudcompare.org/. Accessed 17 February 2021

Deere DU, Deere DW (1989) Rock Quality Designation (RQD) after twenty years. Waterways Experimental Station, Vicksburg, MS: US Army Corps of Engineers Contract.Report GL-89-1.

Dunham L, Wartman J, Olsen MJ, O'Banion M, Cunningham K (2017) Rockfall Activity Index (RAI): a lidar-derived, morphology-based method for hazard assessment. Eng Geol 221:184-192. https://doi. org/10.1016/j.enggeo.2017.03.009

Farmakis I, Marinos V, Papathanassiou G, Karantanellis E (2020) Automated 3D jointed rock mass structural analysis and characterization using LiDAR terrestrial laser scanner for rockfall susceptibility assessment: Perissa area case (Santorini). Geotech Geol Eng 38:3007-3024. https://doi.org/10.1007/s10706-020-01203-x

Gigli G, Morelli S, Fornera S, Casagli N (2014) Terrestrial laser scanner and geomechanical surveys for the rapid evaluation of rock fall susceptibility scenarios. Landslides 11:1-14. https://doi.org/ 10.1007/s10346-012-0374-0

Günther A, Wienhöfer J, Konietzky H (2012) Automated mapping of rock slope geometry, kinematics and stability with RSS-GIS. Nat Hazards 61:29-49. https://doi.org/10.1007/s11069-011-9771-2

Guo J, Liu Y, Wu L, Liu S, Yang T, Zhu W, Zhang Z (2019) A geometryand texture-based automatic discontinuity trace extraction method for rock mass point cloud. Int J Rock Mech Min Sci 124:1-10. https://doi.org/10.1016/j.ijrmms.2019.104132

Irigaray C, Fernández T, Chacón J (2003) Preliminary rock-slopesusceptibility assessment using GIS and the SMR classification. Nat Hazards 30:309-324. https://doi.org/10.1023/B:NHAZ. 0000007178.44617.c6

ISRM (1978) International society for rock mechanics commission on standardization of laboratory and field tests: suggested methods for the quantitative description of discontinuities in rock masses. Int J Rock Mech Min Sci Geomech Abstr 15:319-368

Jordá Bordehore L, Riquelme A, Cano M, Tomás R (2017) Comparing manual and remote sensing field discontinuity collection used in kinematic stability assessment of failed rock slopes. Int J Rock Mech Min Sci 97:24-32. https://doi.org/10.1016/j.ijrmms.2017. 06.004

Makropoulos K, Kaviris G, Kouskouna V (2012) An updated and extended earthquake catalogue for Greece and adjacent areas since 1900. Nat Hazard 12:1425-1430. https://doi.org/10.5194/ nhess-12-1425-2012

Manutsoglu E, Soujon A, Jacobshagen V (2003) Tectonic structure and fabric development of the Plattenkalk unit around the Samaria gorge, Western Crete, Greece. Zeitschrift Der Deutschen Geologischen Gesellschaft 154:85-100. https://doi.org/10.1127/zdgg/ $154 / 2003 / 85$

Matasci B, Stock GM, Jaboyedoff M, Carrea D, Collins BD, Guérin A et al (2018) Assessing rockfall susceptibility in steep and overhanging slopes using three-dimensional analysis of failure mechanisms. Landslides 15:859-878. https://doi.org/10.1007/s10346-017-0911-y

Menegoni N, Giordan D, Perotti C (2020) Reliability and uncertainties of the analysis of an unstable rock slope performed on RPAS digital outcrop models: the case of the Gallivaggio landslide 
(Western Alps, Italy). Remote Sens 12:1-25. https://doi.org/ 10.3390/rs12101635

Menegoni N, Giordan D, Perotti C, Tannant DD (2019) Detection and geometric characterization of rock mass discontinuities using a 3D high-resolution digital outcrop model generated from RPAS imagery-Ormea rock slope, Italy. Eng Geol 252:145-163. https://doi.org/10.1016/j.enggeo.2019.02.028

National Observatory Athens. (2020). Meteo.gr search. http://meteosearch. meteo.gr/. Accessed 5 October 2020

Palmstrom A (2005) Measurements of and correlations between block size and rock quality designation (RQD). Tunn Undergr Space Technol 20:362-377. https://doi.org/10.1016/j.tust.2005.01.005

Papathanassiou G, Riquelme A, Tzevelekis T, Evaggelou E (2020) Rock mass characterization of karstified marbles and evaluation of rockfall potential based on traditional and SfM-based methods: case study of Nestos, Greece. Geosciences 10:1-20. https://doi. org/10.3390/geosciences10100389

Riquelme AJ, Abellán A, Tomás R, Jaboyedoff M (2014a) A new approach for semi-automatic rock mass joints recognition from 3D point clouds. Comput Geosci 68:38-52. https://doi.org/10. 1016/j.cageo.2014.03.014

Riquelme AJ, Abellán A, Tomás R (2015) Discontinuity spacing analysis in rock masses using 3D point clouds. Eng Geol 195:185-195. https://doi.org/10.1016/j.enggeo.2015.06.009

Riquelme AJ, Tomás R, Abellán A (2014b). SMRTool beta. A calculator for determing Slope Mass Rating (SMR). Universidad de Alicante. http://personal.ua.es/es/ariquelme/smrtool.html. Accessed 17 February 2021

Riquelme AJ, Tomás R, Cano M, Pastor JL, Abellán A (2018) Automatic mapping of discontinuity persistence on rock masses using 3D point clouds. Rock Mech Rock Eng 51:3005-3028. https://doi. org/10.1007/s00603-018-1519-9

Romana MR (1993) A geomechanical classification for slopes: Slope Mass Rating. In Hudson JA (ed) Comprehensive Rock Engineering, 1st edn. Elsevier, Exeter, pp. 575-600. https://doi.org/10. 1016/B978-0-08-042066-0.50029-X

Saroglou C (2019) GIS-based rockfall susceptibility zoning in Greece. Geosciences 9:1-21. https://doi.org/10.3390/geosciences9040163

Seidel M (2003) Tectono-sedimentary evolution of middle Miocene supra-detachment basins (western Crete, Greece). Dissertation, Universität zu Köln.

Slob S (2010) Automated rock mass characterisation using 3-D terrestrial laser scanning. Dissertation: International Institute for Geo-information Science and Earth Observation.
Spanos I, Platis P, Meliadis I, Tsiontis A (2008) A review on the ecology and management of the Samaria Gorge, a Greek biosphere reserve. J Geog Reg Plann 1:19-33. https://doi.org/10.5897/JGRP. 9000004

Sturzenegger M, Stead D, Elmo D (2011) Terrestrial remote sensingbased estimation of mean trace length, trace intensity and block size/shape. Eng Geol 119:96-111. https://doi.org/10.1016/j. enggeo.2011.02.005

Thiele ST, Grose L, Samsu A, Micklethwaite S, Vollgger SA, Cruden AR (2017) Rapid, semi-automatic fracture and contact mapping for point clouds, images and geophysical data. Solid Earth 8:12411253. https://doi.org/10.5194/se-8-1241-2017

Ünlüsoy D, Süzen ML (2020) A new method for automated estimation of joint roughness coefficient for 2D surface profiles using power spectral density. Int J Rock Mech Min Sci 125:1-9. https://doi. org/10.1016/j.ijrmms.2019.104156

Vogiatzakis I, Rackham O (2008) Crete. In: Vogiatzakis IN, Pungetti G, Mannion AM (eds.) Mediterranean Island landscapes. Landscape Series. Springer, Dordrecht, vol. 9, pp. 245-270. https://doi.org/ 10.1007/978-1-4020-5064-0_11

Wang S, Zhang Z, Wang C, Zhu C, Ren Y (2019) Multistep rocky slope stability analysis based on unmanned aerial vehicle photogrammetry. Environ Earth Sci 78:1-16. https://doi.org/10.1007/ s12665-019-8145-z

Westoby MJ, Brasington J, Glasser NF, Hambrey MJ, Reynolds JM (2012) "Structure-from-motion" photogrammetry: a low-cost, effective tool for geoscience applications. Geomorphology 179:300-314. https://doi.org/10.1016/j.geomorph.2012.08.021

Yilmaz I, Marschalko M, Yildirim M, Dereli E, Bednarik M (2012) GIS-based kinematic slope instability and slope mass rating (SMR) maps: application to a railway route in Sivas (Turkey). Bull Eng Geol Env 71:351-357. https://doi.org/10.1007/ s10064-011-0384-5

Zhang P, Zhao Q, Tannant DD, Ji T, Zhu H (2019) 3D mapping of discontinuity traces using fusion of point cloud and image data. Bull Eng Geol Env 78:2789-2801. https://doi.org/10.1007/ s10064-018-1280-Z

Zhang Y, Yue P, Zhang G, Guan T, Lv M, Zhong D (2019) Augmented reality mapping of rock mass discontinuities and rockfall susceptibility based on unmanned aerial vehicle photogrammetry. Remote Sens 11:1-34. https://doi.org/10.3390/rs11111311 